\title{
A Novel fuzzy hybrid Neutrosophic decision-making approach for the resilient supplier selection problem
}

Dragan Pamucar, Morteza Yazdani, Radojko Obradovic, Anil Kumar, Mercedes Torres-Jiménez

https://doi.org/10.1002/int.22279

\begin{abstract}
The objectives of this study are to mitigate the risk and disturbances to the supply chain, to offer required models for resolving the complex issues that arise, and to maintain the stability of the support system. Also, the uncertain conditions in a supply chain force decision-makers and experts to adopt a fuzzy-based evaluation platform to ensure secure and reliable consequences. The current study proposed a fuzzy neutrosophic decision-making approach for supplier evaluation and selection. The model is composed of a new weight aggregator that uses pairwise comparison, which has not been reported to date. The model uses a Dombi aggregator that is more qualified than other aggregators. The Dombi t-conorms and t-norms have the same properties as those of the general t-conorm and t-norm, which can enhance the flexibility of the information aggregation process via the adjustment of a parameter. A decision-making environment with uncertain condition and multiple factors is supposed. We applied this approach in a construction company to analyse the suppliers in a resilient supply chain management (RSCM) system using a MABAC (multi-attribute border approximation area comparison) tool. The accuracy of the proposed model was examined via sensitivity analysis tests. This study proposes a novel fuzzy-neutrosophic-based approach for resilient supplier selection. The main contributions of this research work are the design, implementation and analysis of a multi-attribute evaluation system with respect to fuzzy neutrosophic values. In this evaluation system, a new pairwise comparison is conducted with trapezoidal neutrosophic linguistic variables to determine the importance weights of supplier criteria. Typically, the provision of opinions regarding the qualitative performances of suppliers is a difficult and confusing responsibility for experts and supplier evaluators. Therefore, the propsed approach overcomes this problem by utilizing a pairwise comparison by neutrosophic values and proposes original Dombi aggregation operators for dealing with fuzzy neutrosophic sets.
\end{abstract}

Keywords: Fuzzy decision-making, resilient supply chain, neutrosophic sets, MABAC, Dombi aggregators

\section{Introduction}

Companies are focusing on making their supply chains more effective; hence, globally, Supply Chain (SC) complexity is increasing. Digital transformation and resource scarcity, among other factors, are impacting SCs enormously and forcing them to speedily transform. According to the Business Continuity Institute (BCI) (2013), 90 percent of companies do not know their continuity plans with their key suppliers, 75 percent have experienced at least one major SC disruption per year, and 42 percent have experienced a major disruption that is below tier 1 . These data show that the majority of companies do not regularly assess the resilience of their SCs. Resilient Supply Chain (RSC) is a relatively new concept that can be interpreted as the adaptive capability of a SC system to react and respond to unexpected events with the required actions, to respond to disruptions and risk, and to recover from them by maintaining and controlling the operations at the 
desired level ${ }^{42}$. The increased size and complexity of SC operations, the connections among risks and the unexpected elements for SC networks leave decision makers with substantial vagueness and, often, a large volume of incorrect information that is not confidential ${ }^{47}$. Conditions such as these and other types of complexity lead policy makers to re-evaluate how they can interact and take correct action. The performance in this aspect depends on the skill and experience of the management system in dealing with such challenges timely and reducing further consequences. As a fundamental issue, the selection of suitable suppliers becomes one of the key elements in the creation of RSCs. According to Rajesh and Ravi ${ }^{45}$, resilient suppliers are "suppliers who are able to provide good quality products at economy rates and flexible enough to accommodate demand fluctuations with shorter lead times over a lower ambience of risk without compromising on safety and environment practices". Therefore, the ability of suppliers to manage the contingencies and interruptions that are generated in the SC at any moment with agility and flexibility is the embodiment of the resilience of suppliers ${ }^{52}$. However, the selection of resilient providers under conditions of uncertainty has yet to be sufficiently addressed in the literature ${ }^{13,54}$.

In decision-making research, uncertainty is always a highly challenging issue, despite the various concrete and accurate approaches that have been proposed. Research projects inevitably are faced addressing the uncertainty of complex decision-making conditions. Experts are enabled to express and deliver their judgments and preferences using linguistic terms more reliably and conveniently. Therefore, the modelling of expert preferences in decision-making problems using linguistic fuzzy terms represents responsibility and a task that must be managed effectively. For SC management, a wide range of decision-making models has been proposed that incorporate fuzzy and probabilistic approaches. However, SC managers are still dealing with such uncertainty in the design of networks ${ }^{14,43}$, in logistics and transportation support ${ }^{64}$, in supplier selection and management ${ }^{44}$, and inventory management ${ }^{3}$.

Fuzzy sets were developed for responding to and satisfying decision-making requirements if uncertainty is dominant. Many practical decision-making projects that involve imprecise, incomplete, and inconsistent information have been formulated and solved using neutrosophic fuzzy sets and logic. Among the enormous number of approaches that have been designed using fuzzy logic, neutrosophic set utilization and applications in decision-making processes constitute one of the most frequently applied research themes. neutrosophic sets and logic are a generalized form of fuzzy intuitionistic sets and logic ${ }^{27,40,48}$. The neutrosophic sets can address the higher type of uncertainty that is present in natural and human systems. In the last decade, we have witnessed a rapid growth in the use of neutrosophic sets and logic in multiple-criteria decision-making, group decision-making, system optimization and control problems and their applications to 
various fields ${ }^{22,60}$. For example, Pamucar et $\mathrm{al}^{36}$ presented novel multi-criteria decision making (MCDM) pairwise-CODAS model in which the modification of the CODAS method was made using linguistic neutrosophic numbers. By integrating these models with linguistic neutrosophic numbers, it was shown that it is possible to a significant extent to eliminate subjective qualitative assessments and assumptions by decision-makers in complex decision-making conditions. Also, fuzzy theory is very powerful tool for exploiting uncertainty in expert's preferences, Pamucar et $\mathrm{al}{ }^{37}$ used fuzzy theory for prioritizing transportation demand management measures. The authors proposed novel MCDM model based on fuzzy Full Consistency method and hybrid DombiBonferroni aggregator for a case study in Istanbul's urban mobility system. The first paper presents the application of linguistic neutrosophic numbers with CODAS methodology while the second paper proposes an application of fuzzy sets with FUCOM and Dombi-Bonferroni aggregators. Based on the development of neutrosophic decision-making models compared to other fuzzy decision-making areas, the studies on the neutrosophic approach are relatively recent. A few applications of this approach can be found in the literature, and systematic and in-depth research on models and solutions is being planned and conducted ${ }^{25}$. Based on the trend of establishing new theories, methodologies and tools for neutrosophic sets in decision-making theories, this concept is vital and makes a sufficient contribution. Therefore, one of the main objectives of this work is to deepen the knowledge of this topic through the application of the fuzzy neutrosophic decision-making approach.

One of the motivations is to develop a novel approach that modifies the MABAC (Multi-Attribute Border Approximation Area Comparison) model by using trapezoidal fuzzy neutrosophic numbers (TrFNN). Integration of TrFNN and MABAC approach enables decision-makers to express their preferences more realistically and achieve more objective results. Another contribution of the study is the presentation of the Dombi weighted aggregation operators: the TrFNN Dombi weighted arithmetic averaging (TrFNNDWAA) operator and the TrFNN Dombi weighted geometric averaging (TrFNNDWGA) operator that enables the aggregation of expert decisions and the evaluation of alternatives in the TrFNN environment. The Dombi class of operators are used in this study since they successfully eliminate disadvantages of traditional min-max operators in fuzzy environment (Dombi, 1982). Also, Dombi T-norms (TN) and T-conorms (TCN) have general parameters of general $\mathrm{TN}$ and $\mathrm{TCN}$, and this can make the aggregation process more flexible $^{58}$.

In addition, a new methodology for determining criteria weights that uses a pairwise comparison (PW model) was developed in this study. The basic motivation for developing a PW model lies in the fact that the literature considering the application of MCMD techniques in the $\operatorname{TrFNN}$ 
environment is limited to only a few papers. The authors hope that the presentation of a new methodology will motivate the authors. The other intention of the paper is to combine the previous two goals, which corresponds to the formation of a new model for evaluating alternatives that combines TrFNN MABAC and TrFNN PW approaches. To the best of our knowledge, such a model for decision-making in the resilient supplier selection filed has not been observed, and even from this point of view, the importance of this study can be seen.

The paper is organized as follows: The literature is reviewed in Section 2. All the required materials and methods are presented in Section 3. In Section 4, the proposed MADM neutrosophic model is described. To demonstrate the applicability of the proposed model, a case study of a construction company is presented in Section 5. The sensitivity analysis is given in Section 6 and conclusion in Section 7.

\section{Literature review}

This section reviews the literature that is related to resilient supply chains (RSCs) under uncertainty, neutrosophic fuzzy values, and their innovations and contributions.

\subsection{Resilient supply chains under uncertainty}

The term resilience is defined from a multidisciplinary perspective and corresponds to a novel area of scientific research in production and manufacturing, psychology, ecology, and economics. In addition, the resilience viewpoint can be realized from emerging interdisciplinary perspectives, such as emergency management, sustainable development and supply-chain risk management. The classical supply chain structures have relied on typical and relevant factors for the assessment and comparison of suppliers. Previously, companies could rely on several indicators, such as supplier price, delivered quality, technology, service after sale, and stability and flexibility of suppliers. However, currently, due to the occurrence if multi-level and complex scenarios in SCs, a new discipline should be addressed. The main objective of investigators is to comprehensively study this topic. For example, Pramanik et $\mathrm{al}^{43}$ modelled an integrated AHP-QFD and fuzzy TOPSIS for reporting the list of optimal suppliers.

Jüttner and Maklan ${ }^{69}$ considered SC resilience and examined its association with the related supply chain vulnerability (SCV) and supply chain risk management (SCRM) and a case study of three SCs was used to investigate the relationship between the ideas regarding the global financial crisis. Torabi et $\mathrm{al}^{62}$ designed a scenario-based bi-objective possibilistic mixed-integer linear model, which was used to build a robust supply network and to select suppliers to decrease uncertainties and disruptions that are caused by operational risks. Table 1 shows the published work of resilient supplier under uncertainty. 
Table 1: Literature review of resilient supplier selection

\begin{tabular}{|c|c|c|}
\hline Author & Methodology & Area / Application \\
\hline Foroozesh $^{13}$ & $\begin{array}{l}\text { MCGD with interval-valued fuzzy sets } \\
\text { and possibilistic statistical concepts } \\
\text { (mean, standard deviation and the cubic } \\
\text { roots of skewness matrices). }\end{array}$ & $\begin{array}{l}\text { Automobile manufacturer } \\
\text { example). }\end{array}$ \\
\hline Zhao $^{69}$ & IFH-VIKOR & $\begin{array}{l}\text { University teaching hospital (selection of } \\
\text { the supplier of a new information } \\
\text { management system). }\end{array}$ \\
\hline Tooranloo et $\mathrm{al}^{61}$ & Fuzzy AHP & A company that produces composite parts \\
\hline Jain et $\mathrm{al}^{18}$ & $\begin{array}{l}\text { AHP and the technique for order of } \\
\text { preference by similarity to the ideal } \\
\text { solution (TOPSIS) }\end{array}$ & $\begin{array}{l}\text { A supplier selection problem in an Indian } \\
\text { automobile company }\end{array}$ \\
\hline Sahu et $\mathrm{al}^{51}$ & Fuzzy-VIKOR & An automobile manufacturer \\
\hline Fazlollahtabar $^{12}$ & $\begin{array}{l}\text { A fuzzy preference ranking } \\
\text { organization method for enrichment } \\
\text { evaluation (PROMETHEE) and fuzzy } \\
\text { linear programming (FLP) }\end{array}$ & $\begin{array}{l}\text { Case of study that is based on the selection } \\
\text { among appliance manufacturers for } \\
\text { implementing the proposed methodology } \\
\text { under uncertainty. }\end{array}$ \\
\hline Memon et $\mathrm{al}^{31}$ & $\begin{array}{l}\text { Combined grey systems theory and } \\
\text { uncertainty theory }\end{array}$ & $\begin{array}{l}\text { Application for decreasing the } \\
\text { purchasing risks that are associated } \\
\text { with suppliers. }\end{array}$ \\
\hline Rajesh and Ravi ${ }^{45}$ & $\begin{array}{l}\text { Grey relational analysis (mix of a grey } \\
\text { system and uncertainty theory) }\end{array}$ & Electronic supply chain \\
\hline Igoulalene et al ${ }^{17}$ & $\begin{array}{l}\text { Two approaches: the fuzzy TOPSIS } \\
\text { method and the fuzzy consensus-based } \\
\text { neat OWA and goal programming } \\
\text { model. }\end{array}$ & $\begin{array}{l}\text { A group of stakeholders is in charge of the } \\
\text { evaluation of a set of potential alternatives. } \\
\text { These alternatives are evaluated in a fuzzy } \\
\text { environment while considering both } \\
\text { subjective } \\
\text { (qualitative) and objective (quantitative) } \\
\text { criteria. }\end{array}$ \\
\hline Junior et $\mathrm{al}^{23}$ & $\begin{array}{l}\text { Comparative analysis of two methods: } \\
\text { fuzzy AHP and fuzzy TOPSIS }\end{array}$ & $\begin{array}{l}\text { Selection of suppliers of a company in the } \\
\text { automotive production chain }\end{array}$ \\
\hline Deng et $\mathrm{al}^{7}$ & $\begin{array}{l}\text { AHP that is extended with D-numbers } \\
\text { (D-AHP) }\end{array}$ & $\begin{array}{l}\text { Selection of global suppliers (example } \\
\text { obtained from (Chan \& Kumar, 2007). The } \\
\text { hierarchical structure of D-AHP contains } \\
\text { three levels. The D number preference } \\
\text { relation is established for expressing the } \\
\text { experts' judgements. }\end{array}$ \\
\hline Dursun and Karsak ${ }^{10}$ & $\begin{array}{l}\text { QFD (quality function } \\
\text { deployment)-based fuzzy MCDM }\end{array}$ & $\begin{array}{l}\text { An enterprise that manufactures complete } \\
\text { clutch couplings }\end{array}$ \\
\hline Li et $\mathrm{al}^{29}$ & A grey-based rough set approach & $\begin{array}{l}\text { A case that is designed ad-hoc for the } \\
\text { specified application with } 7 \text { suppliers and } \\
4 \text { attributes, which are related to } \\
\text { qualitative and quantitative aspects of the } \\
\text { service quality }\end{array}$ \\
\hline Haldar et al ${ }^{15}$ & & Application in automobile manufacturing \\
\hline
\end{tabular}

\subsection{Neutrosophic fuzzy values}

To handle an uncertain decision process in which imprecise, incomplete, and inconsistent information is dominant, various approaches were developed for approximate and uncertain reasoning. One is the concept of fuzzy logic and its extensions like Intuitionistic, interval, Pythagorean. Among the recent proposals of fuzzy systems is neutrosophic logic (NL), which interpreted by Smarandache $\mathrm{S}^{55}$ as a generalization of fuzzy systems. The fundamental assumption 
of neutrosophy is that every idea has not only a degree of truth but also a falsity degree and an indeterminacy degree, which must be considered independently from one another ${ }^{27}$. Smarandache ${ }^{55}$ proposed the concept of a neutrosophic set from a philosophical viewpoint, which is a powerful general formal framework and generalizes the concepts of the classical fuzzy set ${ }^{67}$, the intuitionistic fuzzy set (IFS) ${ }^{1}$, and the interval-valued intuitionistic fuzzy set (IVIFS) ${ }^{2}$.

A neutrosophic fuzzy set is a general form of unification of fuzzy logic, especially intuitionistic fuzzy $\operatorname{logic}{ }^{56}$. The main strategy behind NL is to characterize a logical statement in a 3dimensional neutrosophic space, where each dimension of the space corresponds to the truth $(\mathrm{T})$, the falsehood (F), and the indeterminacy (I) of the statement under consideration. T, I, and F are standard or non-standard real subsets of $]-0,1+[$ with not necessarily any connection among them $^{66}$. Over a period of 15 years, the increasing development of neutrosophic fuzzy decisionmaking models attracted substantial attention, and currently, investigators rely on that progress to address the complexity and to obtain desirable results. For instance, $\mathrm{Ye}^{66}$ proposed trapezoidal fuzzy neutrosophic sets, numbers and applied them to MADM. Biswas et al ${ }^{4}$ presented cosinesimilarity-measure-based MADM with trapezoidal fuzzy neutrosophic numbers, however, scant research has been conducted on it ${ }^{4,66}$.

Aggregation operators are powerful tools for decision-making, especially in a group-decisionmaking environment ${ }^{20,21}$. Aggregation is the process of combining numerical values into a single number that represents the original set of numbers. The objective of aggregation operators is to combine preferences into a general value while considering all the parts. Various operators were developed in the literature for gathering information about the assessment. The most widely used operators in fuzzy theory are the min operator and the max operator ${ }^{8,19}$. They have many advantages: for example, they are easy to calculate, and they can be extended into a lattice structure. However, in practice, the strict operators are more intensively used. The reason is that in the min-max case, the result is determined only by one variable, and the other variables have no influence, in contrast to the strictly monotonically increasing operators such as those of the Dombi operator class. Dombi ${ }^{9}$ proposed the Dombi T-conorm and T-norm operations, which were applied to aggregation of information in many areas; for example, Dombi hesitant fuzzy information aggregation operators were utilized in the assessment of disasters ${ }^{18}$, and intuitionistic fuzzy set Dombi Bonferroni mean operators were used to aggregate group decisions in multi-criteria decision-making (investment) problems ${ }^{30}$. In addition to the application of the Dombi $t$-conorm and $t$-norm for the aggregation of intuitionistic fuzzy information ${ }^{30}$, they were also used to aggregate hesitant fuzzy information ${ }^{18}$, single-valued neutrosophic information ${ }^{18,65}$, interval neutrosophic information ${ }^{26}$, neutrosophic cubic sets ${ }^{53}$ and rough information ${ }^{49,57}$. Dombi operations 
have yet to be extended to TrFNN, and only a few aggregators have been developed in the TrFNN environment: (1) the TrFNN weighted arithmetic averaging (TrNNWAA) operator ${ }^{66}$, (2) the TrFNN weighted geometric averaging (TrFNNWGA) operator ${ }^{66},(3)$ the TrFNN ordered weighted arithmetic averaging (TrFNNOWAA) operator and (4) the TrFNN hybrid weighted arithmetic averaging (TrFNNHWAA) operator. Hence, the main impact of our paper is in the development of aggregation operators that are based the Dombi operations for handling TrFNN decision-making problems.

\subsection{Novelty and contributions}

The current research work integrates various approaches by using an adopted perspective to evaluate and select resilient suppliers. This study proposes a novel fuzzy-neutrosophic-based approach for resilient supplier selection. The main contributions of this research work are the design, implementation and analysis of a multi-attribute evaluation system with respect to fuzzy neutrosophic values. In this evaluation system, a new pairwise comparison is conducted with trapezoidal neutrosophic linguistic variables to determine the importance weights of supplier criteria. Typically, the provision of opinions regarding the qualitative performances of suppliers is a difficult and confusing responsibility for experts and supplier evaluators. The main novelty of this study is that it overcomes this problem by utilizing a pairwise comparison by neutrosophic values and proposes original Dombi aggregation operators for dealing with TrFNNs. The Dombi $t$ conorms and $t$-norms have the same properties as the general $\mathrm{t}$-conorm and $\mathrm{t}$-norm, and the information aggregation process can be flexibly tuned using a parameter. Thus, Dombi operational laws of TrFNNs are proposed in this study. Then, a TrFNN Dombi weighted arithmetic average (TrFNNDWAA) operator and a TrFNN Dombi weighted geometric average (TrFNNDWGA) operator are presented. Furthermore, a decision-making approach on basis of the TrFNNDWAA or TrFNNDWGA operator is developed for TrFNNDWGA MADM problems.

To ensure that the experts can choose suppliers with high reliability and to realize the objective of obtaining an optimal solution, a TrFNN MABAC method is employed. The performance, reliability and applicability of MABAC are tracked through several studies ${ }^{11,33-36,38}$. It is evident that the results must be evaluated in terms of acceptability using several strategies for sensitivity analysis, and comparisons with other multi-attribute models and a weighted analytical approach are conducted.

\section{Required arithmetic formulas, materials and proposed models}

This section the concepts of single-valued Neurosophic sets are presented, and an aggregator, namely, the Dombi operator, is introduced. This operator is essential for pairwise comparison and for obtaining the weights of the decision factors. Finally, the fuzzy trapezoidal neutrosophic 
MABAC model is established. The TrFNN concept is presented with an expansion of singlevalued neutrosophic sets using trapezoidal fuzzy numbers.

\subsection{Trapezoidal fuzzy neutrosophic numbers (TrFNNs)}

The following definition of a trapezoidal fuzzy neutrosophic set.

Definition 1. $\left(\mathrm{Ye}^{70}\right)$ Let the universe of discourse be . The trapezoidal fuzzy neutrosophic set in has the following form:

where, and are three TrFNNs

, and

under the condition that for .

Definition 2. $\left(\mathrm{Ye}^{70}\right)$ Suppose three trapezoidal fuzzy numbers are denoted as, and . The corresponding trapezoidal fuzzy neutrosophic number is represented as, and it represents the basic element of the trapezoidal fuzzy neutrosophic set. The TrFNN parameters satisfy the following relations: , and . If the conditions, and are satisfied, then $\operatorname{TrFNN}$ reduces to a triangular fuzzy neutrosophic number, which is a special case of $\operatorname{TrFNN}$. TrFNN is presented graphically in Figure 1.

Figure 1. Graphic interpretation of TrFNN

The truth function of TrFNN belonging is defined as:

The indeterminacy function of TrFNN belonging is defined as:

The falsity function of $\mathrm{TrFNN}$ is defined as:

Definition 3. $\left(\mathrm{Ye}^{70}\right)$ Let and be two TrFNNs. We define the following rules for operations with TrFNN:

1)

2)

3)

4)

Based on the expected value of the trapezoidal fuzzy number ${ }^{4}$, the score function and the accuracy function of the neutrosophic number ${ }^{70}$, we propose the following definitions of the resulting function and the accuracy function for TrFNN.

Definition 4 (Biswas et $\mathrm{al}^{4}$ ). Let be a TrFNN. The resulting function of the TrFNN can be defined as follows:

where the function has a higher value for a higher TrFNN value. If the conditions, and are satisfied, expression (5) is transformed into the resulting function of the triangular fuzzy neutrosophic number:

which is a special case of expression (5).

Definition $5\left(\mathrm{Ye}^{70}\right)$. Let be a TrFNN. We can define the accuracy function of TrFNN as follows: 
where a larger value of the function corresponds to higher accuracy of the TrFNN. If the conditions, and are satisfied, expression (7) is transformed into the accuracy function of the triangular fuzzy neutrosophic number:

which is a special case of expression (7).

Example 1. Let be TrFNN, then can define the accuracy function of $\operatorname{TrFNN}$ as follows

Definition 6 (Biswas et $\mathrm{al}^{4}$ ). Let and be two TrFNNs. Additionally, let and represent score functions of and, respectively, and let and represent the accuracy functions of and, respectively. We define the following relationships between TrFNN:

1) If $>$, then $>$;

2) If $=$, and a) if $=$ then $=$, and b) if $>$ then $>$.

Example 2. Let and be two TrFNN, then can define the following relationships between $\operatorname{TrFNN}$ : and, then .

\subsection{Aggregation operators of TrFNNs - The TrFNN Dombi operator}

Definition 7. Let $p$ and $q$ be any two real numbers. Then, the Dombi $T$-norm and $T$-conorm between $p$ and $q$ are defined as follows ${ }^{9}$ :

where and.

According to the Dombi $T$-norm and $T$-conorm, we define the Dombi operations of TrFNNs.

Definition 8. Suppose and are two TrFNN and suppose. The operational laws of TrFNN that are based on the Dombi $T$-norm and $T$-conorm can be defined as follows:

(1) Addition "+"

(2) Multiplication " $\times "$

(1) Scalar multiplication, where

(3) Power, where

Based on TrFNN operators (11)-(14), we propose two Dombi weighted aggregation operators: the TrFNN Dombi weighted arithmetic averaging (TrFNNDWAA) operator and the TrFNN Dombi weighted geometric averaging (TrFNNDWGA) operator.

Definition 9. Let for be $n$ TrFNNs and let represent the weight coefficient of , which satisfies . The TrFNNDWAA and TrFNNDWGA operators (15)-(16) are defined as follows:

Theorem 1. Let for be $n$ TrFNNs. The aggregated results that we obtain via expression (15) represent $\mathrm{TrFNN}$. The aggregated TrFNN is obtained via the following expression: 
where represents the weight coefficient of for, which satisfies .

Proof. If , based on the Dombi operations on TrFNN, which are expressed in Eqns. (11)-(14), we obtain following result:

If , based on Eqn. (15), we obtain the following equation:

If, we obtain the following equation:

Therefore, Theorem 1 holds for, and Eqn. (17) holds for all $n$.

Theorem 2. (Idempotency). Let for be a collection of TrFNNs. If , then .

Proof. Since for , using Eqn. (17), we perform the following calculations:

Therefore, holds.

Theorem 3. (Reducibility). If , the following holds:

Proof. Based on Eqn. (17), the property holds.

Theorem 4. (Boundedness). Let for be a collection of TrFNNs, and let and. Then, .

Proof. Let and. Then, , , , and. It follows that

According to the inequalities above, we conclude that holds.

Theorem 5. (Commutativity). Let TrFNN set be any permutation of . Then, .

Proof. The proof of this property is immediate.

Theorem 6. Let for be $n$ TrFNNs. The aggregation of the results via expression (19) represents TrFNN. Aggregated TrFNN is obtained via the following expression:

where represents the weight coefficient of for, which satisfies .

The proof of Theorem 6 is the same as that of Theorem 1; hence, it is omitted here. The TrFNNDWGA operator also has the following properties:

(1) Idempotency: Let for be a collection of TrFNNs. If , then .

(2) Reducibility: If , the following holds:

(3) Boundedness: Let for be a collection of TrFNNs, and let and . Then, .

(4) Commutativity: Let TrFNN set be any permutation of . Then, .

The proofs of these properties are the same as those for the LNNDWGA operator; hence, they are omitted here.

\section{Multi-criteria model that is based on trapezoidal fuzzy neutrosophic numbers}

In the next section (Section 4.1.), a new approach is used to obtain the weights of the criteria, which utilizes comparative pairwise trapezoidal fuzzy neutrosophic numbers (PW-TrFNN). Then, in Section 4.2 the TrFNN MABAC multi-criteria model is presented and described, which is based on the TrFNN concept (Figure 2). 
Figure 2. TrFNN PW-MABAC model

\subsection{Pair-wise TrFNN model for determining the weights of the criteria}

The PW-TrFNN model is implemented through 4 steps:

Step 1. Formation of expert correspondent matrices of comparison for pairs of criteria $\left(M^{(l)}\right)$. We start from the assumption that the comparison of pairs of evaluation criteria (where $\mathrm{n}$ represents the total number of criteria) is performed by m experts. Experts are assigned weight coefficients, , which satisfy and. The comparison of pairs of criteria is based on the pre-defined TrFNN set. Each expert () compares pairs of criteria; therefore, for each expert, we construct a corresponding initial matrix of comparison for pairs of criteria

where and $\mathrm{n}$ represents the number of evaluation criteria. All elements of the matrix (20) on the diagonal () are assigned neutral values from the predefined scale of $\operatorname{TrFNN}$. The matrix elements (20) that are located below the diagonal of the matrix are determined by expression (21)

Trapezoidal fuzzy neutrosophic expressions, namely, , and, independently present information on the degrees of truthfulness, uncertainty and falsehood, respectively, of experts' preferences during the comparison of pairs of criteria .

Step 2. Formation of the aggregated matrix of comparisons of pairs of criteria $(M)$. The final aggregated matrix of comparison of pairs $M$ is obtained via expression (17) or (19).

where elements, , and are obtained by applying the TrFNNDWAA (17) or TrFNNDWGA (19) operator.

Step 3. Determining the deviation between the elements of the aggregated matrix $N$. If there are small deviations between values () and other values within the criterion (), then the criterion has a small influence on the ranking of the alternatives and a small value of the weight coefficient. In contrast, if there are significant deviations between values () and other values within the criterion (), then the criterion has a substantial influence on the ranking of the alternatives and the weight coefficient has a large value. Finally, if all the values of are identical within the criterion (), then the criterion has no effect on the ranking of the alternatives, and the value of the weight coefficient is .

To define the above deviations, we calculate the cosine similarity measure between the elements of the matrix $N$, namely, (), within the criteria ():

where represents the cosine similarity measure between () and (). After that, the cosine similarity measure is calculated between all elements within the framework of the observed criterion ():

Hence, the cosine similarity measure of all the criteria in the matrix $M$ is obtained:

Step 4. Calculation of the optimal values of the weight coefficients of the criteria (). The optimal values of the weight coefficients are obtained via the expression, where () represent the optimal values of the weight coefficients of the criteria and .

\subsection{TrFNN MABAC method}

In this section, the algorithm of the modified TrFNN MABAC method is presented, which consists of six steps:

Step 1. Construction of the initial decision matrix $(N)$. As with the TrFNN PW method, the evaluation of the alternatives according to the criteria is conducted by $m$ experts with assigned 
weight coefficients such that and . For the final ranking of the alternatives (), each expert () evaluates the alternative according to a defined set of criteria. Therefore, for each expert, we construct an initial matrix of decision-making:

where elements of the matrix , namely, , represent TrFNN numbers from a predefined TrFNN linguistic scale. The final aggregated decision matrix is obtained by averaging the matrix elements (26) using expression (17) or (19).

Step 2. Normalization of the initial decision matrix $(N)$. Normalization of the matrix elements yields a matrix ; where, and. The elements of the matrix are obtained via expression (27).

where $B$ and $C$ represent sets of criteria of benefit and cost types, respectively.

Step 3. Calculation of the elements of the weighted matrix $(D)$. The elements of the weighted matrix are obtained by applying expression (28).

Step 4. Calculation of the elements of the boundary approximate area (BAA). The elements of the matrix are obtained by applying expression (29).

Step 5. Calculation of the distance matrix of alternatives from the boundary approximate domain $(S)$. The elements of the matrix are obtained by applying expression (30).

where the distance is determined via expression (31).

Step 6. Ranking of the alternatives. Based on the values of the criterion functions of the alternatives (), the alternatives are ranked. The criterion functions are obtained via expression (32).

The top alternative is determined based on the value, where it is preferable for the alternative to have the highest value of the criterion function .

\section{Case study, model establishment and results}

To demonstrate the applicability of the proposed method, a case study is conducted to measure the evaluation of suppliers for a construction company in Madrid, Spain. Madrid is a dynamic cosmopolitan urban area, and during the last five years, it grew enormously in terms of the logistic and supply chain division. After the intense crisis in Spain in 2007-2008, the economic and financial conditions are directed effectively and are moving towards a global figure. In this study, a construction company, namely, DOVHER is considered for applying the proposed method. The manager of the company established a function for reducing the risk and disruption of the operations, and the supply chain department decided to evaluate suppliers. The objective is to identify the fundamental drivers and practices of the supply network. We refer to the total set of drivers and practices as decision criteria. The resilience drivers can be labelled as $\mathrm{C}_{1}$ (top management support), $\mathrm{C}_{2}$ (reputation), $\mathrm{C}_{3}$ (corporate strategy $\&$ commitment), $\mathrm{C}_{4}$ (customer/community pressures), $\mathrm{C}_{5}$ (economic stability), $\mathrm{C}_{6}$ (logistics-optimized infrastructure), 
and $\mathrm{C}_{7}$ (environmental conservation). The practices that are associated with resilience are labelled as $\mathrm{C}_{8}$ (vulnerability and collaboration in risk reduction), $\mathrm{C}_{9}$ (supplier's sustainability), $\mathrm{C}_{10}$ (supply chain velocity), $\mathrm{C}_{11}$ (supplier responsiveness) and $\mathrm{C}_{12}$ (training). We have invited company experts and obtained the information from 8 suppliers (logistic providers A1 to A8) who participated in this process. Three experts from engineering, marketing and sales departments who have sufficient experience have been called to attend a meeting to rate the factors. A questionnaire was filled based on fuzzy neutrosophic variables (Table 2) by the experts as Table 3 and provided their opinions regarding the decision criteria and supplier evaluation using linguistic measures.

Table 2. Linguistic values of TrFNNs for linguistic terms

\begin{tabular}{lc}
\hline \multicolumn{1}{c}{ Linguistic terms } & Linguistic values of TrFNNs \\
\hline Absolutely low (AL) & $\langle(0.1,0.1,0.1,0.1),(0.1,0.1,0.1,0.1)$, \\
& $(0.1,0.1,0.1,0.1)\rangle$ \\
Low (L) & $(0.1,0.1,0.2,0.3)\rangle$ \\
Fairly low (FL) & $(0.1,0.1,0.2,0.3),(0.1,0.1,0.2,0.3)$, \\
& $\langle(0.1,0.2,0.3,0.4),(0.1,0.2,0.3,0.4)$, \\
Medium (M) & $(0.3,0.4,0.5,0.6),(0.2,0.4,0.5,0.7), 0.5,0.7)\rangle$ \\
Fairly high (FH) & $(0.4,0.6,0.7,0.9)\rangle$ \\
& $\langle(0.5,0.6,0.7,0.8),(0.4,0.6,0.7,0.9)$, \\
High (H) & $(0.7,0.8,0.9,0.9)\rangle$ \\
Absolutely high (AH) & $(0.7,0.8,0.9,0.9),(0.7,0.8,0.9,0.9)$, \\
& $\langle(0.9,0.9,0.9,0.9),(0.9,0.9,0.9,0.9)$, \\
\end{tabular}

Table 3. Information on the decision-making experts in DOVHER

\begin{tabular}{|c|c|c|c|c|c|c|}
\hline 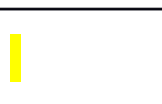 & Gender & Age & $\begin{array}{c}\text { Education } \\
\text { level }\end{array}$ & $\begin{array}{c}\text { Experienc } \\
\mathrm{e}\end{array}$ & Job title & Job responsibilities \\
\hline Expert 1 & Female & 46 & $\begin{array}{l}\text { Bachelor's } \\
\text { in } \\
\text { construction } \\
\text { management }\end{array}$ & $>15$ & $\begin{array}{l}\text { Purchasing } \\
\text { manager }\end{array}$ & $\begin{array}{l}\text { Evaluation, selection and } \\
\text { monitoring existing and new } \\
\text { suppliers and controlling the } \\
\text { quality of materials and } \\
\text { services }\end{array}$ \\
\hline Expert 2 & Male & 52 & $\begin{array}{l}\mathrm{PhD} \text { in } \\
\text { architecture } \\
\text { and urban } \\
\text { design }\end{array}$ & $>18$ & CEO & $\begin{array}{l}\text { Design, planning and } \\
\text { configuration of the required } \\
\text { infrastructures for construction } \\
\text { projects }\end{array}$ \\
\hline Expert 3 & Male & 42 & $\begin{array}{l}\text { Master's in } \\
\text { civil and } \\
\text { construction }\end{array}$ & $>12$ & Architect & $\begin{array}{l}\text { Assisting in construction } \\
\text { projects and supervising. }\end{array}$ \\
\hline
\end{tabular}


Three experts () were involved in the research, and the experts were assigned weight coefficients of , and . Criteria (C1-C12) and alternatives (A1-A8) were evaluated using a set of linguistic terms (Table 2). The following section presents the application of the TrFNN PW-MABAC model through these two phases. (as emphasized earlier in section 4),

Phase I - Determining the weights of the criteria - TrFNN PW model

Step 1: In the first step, each of the experts compared pairs of evaluation criteria using the linguistic scale that is presented in Table 2. Expert comparisons of the criteria are presented in Table 4.

Table 4. Comparisons of pairs of criteria

\begin{tabular}{|c|c|c|c|c|c|c|c|c|c|c|c|c|}
\hline \multicolumn{13}{|c|}{ Expert 1} \\
\hline Criteria & $\mathrm{C} 1$ & $\mathrm{C} 2$ & $\mathrm{C} 3$ & $\mathrm{C} 4$ & $\mathrm{C} 5$ & $\mathrm{C} 6$ & C7 & $\mathrm{C} 8$ & C9 & $\mathrm{C} 10$ & C11 & $\begin{array}{c}\mathrm{C} \\
12 \\
\end{array}$ \\
\hline $\mathrm{C} 1$ & M & $\mathrm{H}$ & M & $\mathrm{H}$ & $\mathrm{L}$ & $\mathrm{L}$ & $\mathrm{H}$ & M & FL & $\mathrm{AL}$ & FL & $\begin{array}{l}\mathrm{F} \\
\mathrm{L}\end{array}$ \\
\hline $\mathrm{C} 2$ & & $\mathrm{M}$ & $\mathrm{M}$ & FH & $\mathrm{M}$ & $\mathrm{M}$ & $\mathrm{L}$ & M & $\mathrm{M}$ & L & $\mathrm{H}$ & $\mathrm{H}$ \\
\hline $\mathrm{C} 3$ & & & M & $\mathrm{H}$ & M & $\mathrm{L}$ & $\mathrm{L}$ & $\mathrm{AL}$ & $\mathrm{H}$ & FL & M & $\mathrm{M}$ \\
\hline $\mathrm{C} 4$ & & & & $\mathrm{M}$ & $\mathrm{H}$ & $\mathrm{L}$ & $\mathrm{M}$ & L & $\mathrm{H}$ & $\mathrm{M}$ & $\mathrm{H}$ & $\mathrm{H}$ \\
\hline $\mathrm{C} 5$ & & & & & M & M & M & $\mathrm{L}$ & M & M & $\mathrm{H}$ & $\mathrm{L}$ \\
\hline C6 & & & & & & $\mathrm{M}$ & M & $\mathrm{H}$ & $\mathrm{L}$ & M & M & F \\
\hline $\mathrm{C} 7$ & & & & & & & M & $\mathrm{H}$ & $\mathrm{L}$ & M & M & $\mathrm{L}$ \\
\hline $\mathrm{C} 8$ & & & & & & & & M & M & $\mathrm{H}$ & $\mathrm{L}$ & M \\
\hline C9 & & & & & & & & & $\mathrm{M}$ & $\mathrm{M}$ & $\mathrm{AL}$ & $\mathrm{M}$ \\
\hline $\mathrm{C} 10$ & & & & & & & & & & $\mathrm{M}$ & L & L \\
\hline C11 & & & & & & & & & & & M & $\mathrm{H}$ \\
\hline $\mathrm{C} 12$ & & & & & & & & & & & & $\mathrm{M}$ \\
\hline \multicolumn{13}{|c|}{ Expert 2} \\
\hline Criteria & $\mathrm{C} 1$ & $\mathrm{C} 2$ & $\mathrm{C} 3$ & $\mathrm{C} 4$ & C5 & C6 & $\mathrm{C} 7$ & $\mathrm{C} 8$ & C9 & $\mathrm{C} 10$ & $\mathrm{C} 11$ & $\begin{array}{c}\mathrm{C} \\
12\end{array}$ \\
\hline $\mathrm{C} 1$ & $\mathrm{M}$ & $\mathrm{M}$ & $\bar{M}$ & $\mathrm{H}$ & $\mathrm{L}$ & $\mathrm{H}$ & $\mathrm{H}$ & $\bar{M}$ & $\mathrm{H}$ & $\mathrm{AL}$ & $\bar{M}$ & $\mathrm{~L}$ \\
\hline $\mathrm{C} 2$ & & $\mathrm{M}$ & $\mathrm{L}$ & $\mathrm{FH}$ & $\mathrm{M}$ & $\mathrm{H}$ & $\mathrm{H}$ & $\mathrm{L}$ & M & M & M & $\mathrm{H}$ \\
\hline $\mathrm{C} 3$ & & & M & $\mathrm{H}$ & $\mathrm{L}$ & $\mathrm{L}$ & $\mathrm{L}$ & $\mathrm{H}$ & $\mathrm{H}$ & FL & M & $\mathrm{H}$ \\
\hline $\mathrm{C} 4$ & & & & M & $\mathrm{H}$ & $\mathrm{L}$ & M & $\mathrm{L}$ & $\mathrm{H}$ & M & $\mathrm{H}$ & $\mathrm{H}$ \\
\hline $\mathrm{C} 5$ & & & & & M & M & M & FL & $\mathrm{H}$ & M & M & $\mathrm{L}$ \\
\hline C6 & & & & & & $\mathrm{M}$ & $\mathrm{AL}$ & $\mathrm{H}$ & L & $\mathrm{H}$ & $\mathrm{H}$ & $\mathrm{M}$ \\
\hline $\mathrm{C} 7$ & & & & & & & M & M & $\mathrm{L}$ & M & $\mathrm{L}$ & $\mathrm{L}$ \\
\hline C8 & & & & & & & & $\mathrm{M}$ & $\mathrm{M}$ & $\mathrm{H}$ & $\mathrm{H}$ & $\mathrm{M}$ \\
\hline C9 & & & & & & & & & M & $\mathrm{L}$ & $\mathrm{AH}$ & $\mathrm{L}$ \\
\hline $\mathrm{C} 10$ & & & & & & & & & & M & $\mathrm{H}$ & $\mathrm{L}$ \\
\hline C11 & & & & & & & & & & & M & $\mathrm{H}$ \\
\hline
\end{tabular}




\begin{tabular}{|c|c|c|c|c|c|c|c|c|c|c|c|c|}
\hline $\mathrm{C} 12$ & & & & & & & & & & & & $\bar{M}$ \\
\hline \multicolumn{13}{|c|}{ Expert 3} \\
\hline Criteria & $\mathrm{C} 1$ & $\mathrm{C} 2$ & $\mathrm{C} 3$ & $\mathrm{C} 4$ & C5 & C6 & C7 & $\mathrm{C} 8$ & C9 & $\mathrm{C} 10$ & C11 & $\begin{array}{c}\mathrm{C} \\
12\end{array}$ \\
\hline $\mathrm{C} 1$ & $\mathrm{M}$ & $\mathrm{L}$ & $\mathrm{M}$ & $\mathrm{M}$ & $\mathrm{L}$ & $\mathrm{H}$ & $\mathrm{M}$ & $\mathrm{H}$ & $\mathrm{H}$ & $\mathrm{M}$ & $\mathrm{M}$ & $\mathrm{L}$ \\
\hline $\mathrm{C} 2$ & & $\mathrm{M}$ & $\mathrm{L}$ & FH & $\mathrm{L}$ & $\mathrm{H}$ & $\mathrm{L}$ & $\mathrm{H}$ & $\mathrm{M}$ & L & FL & $\mathrm{L}$ \\
\hline $\mathrm{C} 3$ & & & M & $\mathrm{M}$ & FL & $\mathrm{H}$ & $\mathrm{H}$ & $\mathrm{M}$ & M & $\mathrm{L}$ & $\mathrm{H}$ & $\mathrm{H}$ \\
\hline $\mathrm{C} 4$ & & & & $\mathrm{M}$ & $\mathrm{H}$ & $\mathrm{L}$ & FL & $\mathrm{L}$ & $\mathrm{H}$ & M & $\mathrm{H}$ & $\mathrm{H}$ \\
\hline $\mathrm{C} 5$ & & & & & M & M & $\mathrm{H}$ & FL & $\mathrm{H}$ & $\mathrm{H}$ & M & $\mathrm{L}$ \\
\hline C6 & & & & & & M & $\mathrm{H}$ & $\mathrm{H}$ & M & $\mathrm{L}$ & $\mathrm{FL}$ & M \\
\hline $\mathrm{C} 7$ & & & & & & & M & $\mathrm{M}$ & $\mathrm{L}$ & $\mathrm{H}$ & $\mathrm{L}$ & $\mathrm{L}$ \\
\hline $\mathrm{C} 8$ & & & & & & & & $\mathrm{M}$ & M & $\mathrm{H}$ & $\mathrm{H}$ & M \\
\hline C9 & & & & & & & & & M & M & $\mathrm{AH}$ & $\mathrm{L}$ \\
\hline $\mathrm{C} 10$ & & & & & & & & & & M & FL & $\mathrm{L}$ \\
\hline C11 & & & & & & & & & & & M & $\begin{array}{l}\mathrm{F} \\
\mathrm{L}\end{array}$ \\
\hline $\mathrm{C} 12$ & & & & & & & & & & & & $\mathrm{M}$ \\
\hline
\end{tabular}

The elements below the diagonal in the expert matrices are defined by expression (21).

Step 2: In this step, the aggregation of the expert correspondence matrices (Table 4) was performed in the aggregated matrix of expert comparisons of the criteria (Appendix, Table A1). The aggregation was conducted using TrFNNDWAA via expression (17). The aggregation of the elements at the $\mathrm{C} 1-\mathrm{C} 2$ positions of Table A1 was conducted using expression (17) as follows:

The aggregation of the remaining elements of matrix $N^{(l)}$ is conducted via the same approach. Steps 3 and 4: Using the expressions (23) - (25), the deviations are calculated between all elements of the aggregated matrix (Table A1). As previously discussed, the smaller the deviation of the values and other values within the observed criterion, the smaller the value of the weight coefficient of the criterion. Additionally, with increasing deviations, the value of the weight coefficient of the criterion increases. The total deviations by the criterion groups, which are calculated via expression (25), and the final values of the weight coefficients of the criteria are presented in Table 5 .

Table 5. Total deviations by criterion group

\begin{tabular}{ccc}
\hline Criteria & & $w_{j}$ \\
\hline C1 & 0.1902 & 0.0563 \\
C2 & 0.1906 & 0.0564 \\
C3 & 0.2565 & 0.0759 \\
C4 & 0.2797 & 0.0828 \\
C5 & 0.2977 & 0.0881 \\
C6 & 0.2728 & 0.0807 \\
C7 & 0.2295 & 0.0679 \\
C8 & 0.3271 & 0.0968 \\
C9 & 0.2726 & 0.0807 \\
C10 & 0.3349 & 0.0991 \\
C11 & 0.2923 & 0.0865 \\
C12 & 0.4345 & 0.1286 \\
\hline
\end{tabular}


The final values of the weight coefficients of the criteria were obtained via the additive normalization of the deviations by groups of criteria .

Phase II - Evaluation of the alternatives - TrFNN MABAC model

After the calculation of the weight coefficients of the criteria, in the second phase, the alternatives were evaluated. Three experts evaluated eight alternatives, which were labelled as A1-A8. For the evaluation of the alternatives, the linguistic scale was used, which is presented in Table 2.

Step 1: To determine the initial decision matrix, experts evaluated alternatives according to the criteria. The initial expert matrices of decision-making are presented in Table 6.

Table 6. Expert correspondence matrices ()

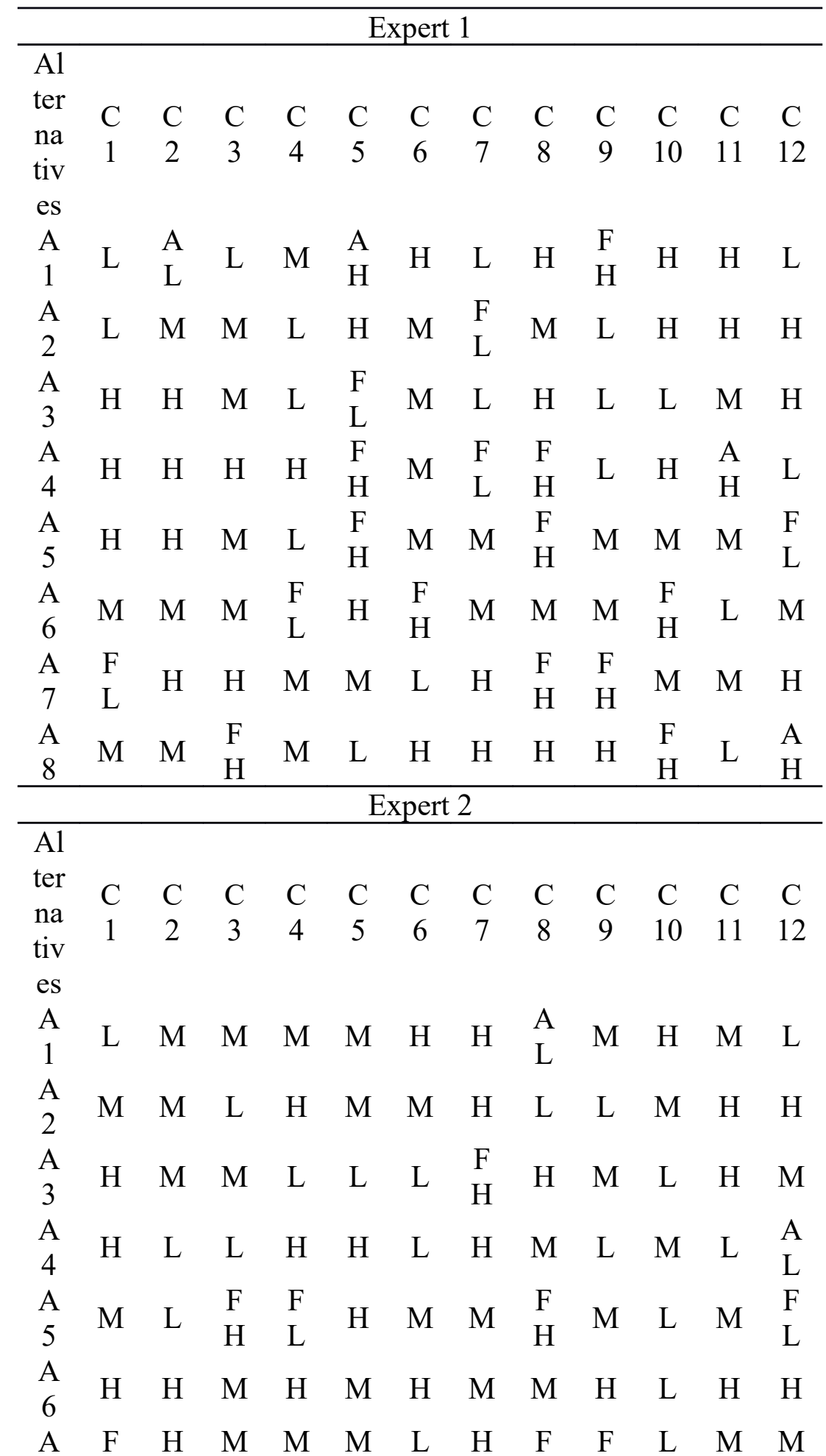




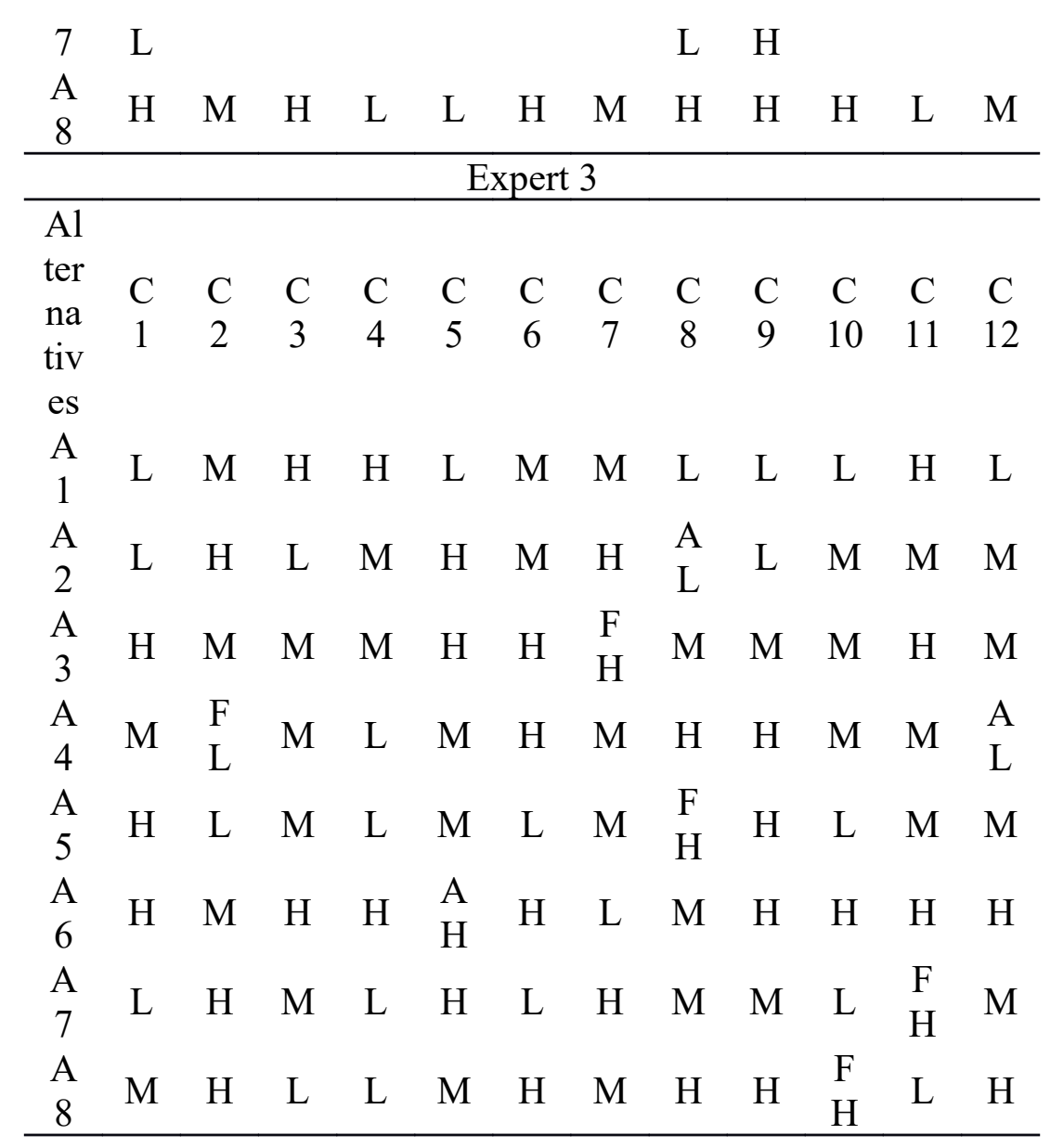

The final aggregated decision matrix $N$ was obtained by averaging the expert correspondence matrices (Table 4) using TrFNNDWGA via expression (19). The aggregated initial decision matrix is presented in Table A2. The elements at positions C1-A2 from Table A2 were aggregated using expression (19) as follows:

The remaining elements of the matrix $N$ were aggregated via the same approach.

Steps 2 and 3: In the second step, using expression (27), normalization was performed, while by applying expression (28), the weights of the elements of the normalized aggregated decision matrix were calculated. The weight matrix $D$ is presented in Table A3. The element at position C1-A2 of Table A3 was obtained using expression (28) as follows:

The remaining elements of the weighting matrix $D$ were obtained via the same approach.

Step 4: Based on the elements of the decision-making weight matrix (Table A3), using expression (29), the elements of the boundary approximate domain matrix were obtained, which is presented in Table 7.

Table 7. BAA matrix

\begin{tabular}{cc}
\hline Criteria & BAA \\
\hline \multirow{2}{*}{ C1 } & $\langle(0.020,0.020,0.020,0.020),(0.953,0.967,0.981,0.984)$, \\
& $(0.953,0.967,0.981,0.984)\rangle$
\end{tabular}




\begin{tabular}{|c|c|}
\hline Criteria & BAA \\
\hline $\mathrm{C} 2$ & $\begin{array}{c}\langle(0.020,0.020,0.020,0.020),(0.958,0.973,0.985,0.988), \\
(0.958,0.973,0.985,0.988)\rangle\end{array}$ \\
\hline $\mathrm{C} 3$ & $\begin{array}{c}\langle(0.022,0.022,0.022,0.022),(0.929,0.955,0.972,0.981), \\
(0.929,0.955,0.972,0.981)\rangle\end{array}$ \\
\hline $\mathrm{C} 4$ & $\begin{array}{c}\langle(0.017,0.017,0.017,0.017),(0.914,0.940,0.963,0.972), \\
(0.914,0.940,0.963,0.972)\rangle\end{array}$ \\
\hline $\mathrm{C} 5$ & $\begin{array}{c}\langle(0.032,0.032,0.032,0.032),(0.949,0.964,0.977,0.982), \\
(0.949,0.964,0.977,0.982)\rangle\end{array}$ \\
\hline C6 & $\begin{array}{c}\langle(0.029,0.029,0.029,0.029),(0.933,0.955,0.974,0.980), \\
(0.933,0.955,0.974,0.980)\rangle\end{array}$ \\
\hline $\mathrm{C} 7$ & $\begin{array}{c}\langle(0.022,0.022,0.022,0.022),(0.946,0.966,0.980,0.986), \\
(0.946,0.966,0.980,0.986)\rangle\end{array}$ \\
\hline $\mathrm{C} 8$ & $\begin{array}{c}\langle(0.037,0.037,0.037,0.037),(0.920,0.949,0.968,0.981), \\
(0.920,0.949,0.968,0.981)\rangle\end{array}$ \\
\hline C9 & $\begin{array}{c}\langle(0.026,0.026,0.026,0.026),(0.927,0.951,0.970,0.980), \\
(0.927,0.951,0.970,0.980)\rangle\end{array}$ \\
\hline $\mathrm{C} 10$ & $\begin{array}{c}\langle(0.027,0.027,0.027,0.027),(0.909,0.939,0.963,0.974), \\
(0.909,0.939,0.963,0.974)\rangle\end{array}$ \\
\hline $\mathrm{C} 11$ & $\begin{array}{c}\langle(0.030,0.030,0.030,0.030),(0.940,0.959,0.974,0.980), \\
(0.940,0.959,0.974,0.980)\rangle\end{array}$ \\
\hline $\mathrm{C} 12$ & $\begin{array}{c}\langle(0.040,0.040,0.040,0.040),(0.899,0.925,0.952,0.960), \\
(0.899,0.925,0.952,0.960)\rangle\end{array}$ \\
\hline
\end{tabular}

Steps 5 and 6: Based on the BAA matrix, using expressions (30) and (31), the distances of the elements of the weight matrix (Table A3) were calculated from the elements of the BAA matrix. Thus, we obtain the distance matrix (S), which is presented in Table 8.

Table 8. Alternative distance matrix from BAA

\begin{tabular}{ccccccccc}
\hline $\begin{array}{c}\text { Criteri } \\
\text { a }\end{array}$ & \multirow{2}{*}{ A1 } & \multirow{2}{*}{ A2 } & A3 & A4 & A5 & A6 & A7 & A8 \\
\hline C1 & 0.00018 & 0.00016 & 0.00055 & 0.00010 & 0.00008 & 0.00008 & 0.00017 & 0.00001 \\
C2 & 0.00013 & 0.00001 & 0.00001 & 0.00003 & 0.00003 & 0.00001 & 0.00055 & 0.00001 \\
C3 & 0.00002 & 0.00018 & 0.00011 & 0.00003 & 0.00007 & 0.00004 & 0.00006 & 0.00002 \\
C4 & 0.00012 & 0.00002 & 0.00017 & 0.00009 & 0.00016 & 0.00008 & 0.00014 & 0.00017 \\
C5 & 0.00010 & 0.00014 & 0.00012 & 0.00011 & 0.00011 & 0.00023 & 0.00003 & 0.00055 \\
C6 & 0.00020 & 0.00017 & 0.00004 & 0.00004 & 0.00023 & 0.00055 & 0.00037 & 0.00108 \\
C7 & 0.00002 & 0.00003 & 0.00005 & 0.00002 & 0.00012 & 0.00015 & 0.00085 & 0.00003 \\
C8 & 0.00015 & 0.00038 & 0.00026 & 0.00008 & 0.00023 & 0.00020 & 0.00020 & 0.00144 \\
C9 & 0.00009 & 0.00030 & 0.00018 & 0.00007 & 0.00003 & 0.00021 & 0.00010 & 0.00120 \\
C10 & 0.00009 & 0.00011 & 0.00031 & 0.00011 & 0.00031 & 0.00002 & 0.00031 & 0.00069 \\
C11 & 0.00016 & 0.00021 & 0.00016 & 0.00014 & 0.00028 & 0.00003 & 0.00018 & 0.00049 \\
C12 & 0.00093 & 0.00056 & 0.00009 & 0.00027 & 0.00094 & 0.00044 & 0.00009 & 0.00074 \\
\hline Qi & 0.00218 & 0.00226 & 0.00205 & 0.00109 & 0.00259 & 0.00204 & 0.00304 & 0.00644 \\
\hline Rank & 5 & 4 & 6 & 8 & 3 & 7 & 2 & 1 \\
\hline
\end{tabular}


By summarizing the elements of the matrix $S$ using expression (30), we obtain the final values of the criterion functions of the alternatives. From the set of alternatives $A i(i=1,2, \ldots, 8)$, we choose an alternative that corresponds to the highest value of the criterion function $\left(Q_{i}\right)$. The values of the criterion functions and the ranks of the alternatives are presented in Table 6.

\section{Comparisons, sensitivity analysis and discussions}

The results are discussed in four parts. In the first part of the discussion of the results, the sensitivity of the TrFNN PW-MABAC model was analysed by changing the weight coefficients of the criteria. The weight coefficients of the criteria were changed in the sensitivity analysis in 21 scenarios. In the second part, the impact of the dynamic matrices of decision-making on the rankings of the alternatives was analysed. In the third part, the results that were obtained with the following TrFNN MCDM models were compared: TrFNN TOPSIS ${ }^{50}$, the TrFNN ordered weighted arithmetic averaging (TrFNNOWAA) $\operatorname{model}^{59}$, the $\mathrm{TrFNN}$ hybrid weighted arithmetic averaging (TrFNNHWAA) model ${ }^{59}$, fuzzy TOPSIS method ${ }^{41}$, fuzzy MABAC method $^{5}$ and rough MABAC method ${ }^{39,59}$. The fourth section presents an analysis of the dependence of the obtained results on the value of the parameter $\rho$. A more detailed overview of the results is presented in the next sections of the paper.

\subsection{Changing the weights of the criteria}

After determining the weight coefficients of the criteria by using TrFNN PW, the "most influential criterion" was identified for the sensitivity analysis. The objective of the sensitivity analysis is to estimate the impact of the "most influential criterion" on the ranking performance of the proposed model. Based on the recommendations of Kirkwood ${ }^{28}$ and Kahraman ${ }^{24}$, the proportionality of the weights of the criteria during the sensitivity analysis (Eq. (33)) and the elasticity coefficient () were defined. The elasticity coefficient was used to express the relative compensation of the values of other weight coefficients in response to changes in the weight of the most important criterion.

where represents the weight of a sensitive criterion (the most important criterion), represents the original value of the weight of the criterion (obtained using the TrFNN PW model) and represents the sum of the original values of the weights of the criteria that are changing.

The parameter represents the size of the change that is applied to a set of weight coefficients, which depends on the coefficient of weight elasticity. The parameter can be (1) positive, which corresponds to an increase in the relative significance, or (2) negative, which corresponds to a decrease in the relative significance. The boundaries of are defined as the largest weight changes in the most important criterion in the negative and positive directions.

In this study, the C12 criterion was identified as the most influential since it corresponded to the largest value of the weight coefficient. In the next step, the coefficient of the weight elasticity () of the most important criterion (Table 9) was determined, and the limits for changing the weight coefficient of the most important criterion () were defined.

Table 9. Coefficients of elasticity for changing weights

\begin{tabular}{cccc}
\hline Criteria & \multicolumn{3}{c}{ Criteria } \\
\hline C1 & 0.0646 & C7 & 0.0780
\end{tabular}




\begin{tabular}{cccc} 
C2 & 0.0647 & C8 & 0.1111 \\
C3 & 0.0871 & C9 & 0.0926 \\
C4 & 0.0950 & C10 & 0.1138 \\
C5 & 0.1011 & C11 & 0.0993 \\
C6 & 0.0926 & C12 & 1.0000 \\
\hline
\end{tabular}

Thus, the limit values of the C12 criteria, which are $-0.1286 \leq \leq 0.8714$, are obtained. Based on the defined limits for changes of the weight coefficient of the most important criterion, the scenarios for the sensitivity analysis have been determined. Interval $-0.1286 \leq 0.8714$ was divided into 21 scenarios. After defining the limit values of the most influential criterion, new values of the weight coefficients for 21 scenarios were defined, which are listed in Table 10.

Table 10. New criterion weights

\begin{tabular}{|c|c|c|c|c|c|c|c|c|c|c|c|c|}
\hline $\begin{array}{c}\text { Scenari } \\
\text { o }\end{array}$ & $\mathrm{C} 1$ & $\mathrm{C} 2$ & C3 & $\mathrm{C} 4$ & C5 & C6 & C7 & C8 & C9 & $\mathrm{C} 10$ & C11 & C12 \\
\hline S1 & 0.0646 & 0.0647 & 0.0871 & 0.0950 & 0.1011 & 0.0926 & 0.0780 & 0.1111 & 0.0926 & 0.1138 & 0.0993 & 0.0000 \\
\hline S2 & 0.0614 & 0.0615 & 0.0828 & 0.0903 & 0.0961 & 0.0880 & 0.0741 & 0.1056 & 0.0880 & 0.1081 & 0.0943 & 0.0500 \\
\hline S3 & 0.0582 & 0.0583 & 0.0784 & 0.0855 & 0.0910 & 0.0834 & 0.0702 & 0.1000 & 0.0833 & 0.1024 & 0.0894 & 0.1000 \\
\hline S4 & 0.0549 & 0.0550 & 0.0741 & 0.0808 & 0.0859 & 0.0788 & 0.0663 & 0.0944 & 0.0787 & 0.0967 & 0.0844 & 0.1500 \\
\hline S5 & 0.0517 & 0.0518 & 0.0697 & 0.0760 & 0.0809 & 0.0741 & 0.0624 & 0.0889 & 0.0741 & 0.0910 & 0.0794 & 0.2000 \\
\hline S6 & 0.0485 & 0.0486 & 0.0653 & 0.0713 & 0.0758 & 0.0695 & 0.0585 & 0.0833 & 0.0695 & 0.0853 & 0.0745 & 0.2500 \\
\hline S7 & 0.0452 & 0.0453 & 0.0610 & 0.0665 & 0.0708 & 0.0649 & 0.0546 & 0.0778 & 0.0648 & 0.0796 & 0.0695 & 0.3000 \\
\hline S8 & 0.0420 & 0.0421 & 0.0566 & 0.0618 & 0.0657 & 0.0602 & 0.0507 & 0.0722 & 0.0602 & 0.0739 & 0.0645 & 0.3500 \\
\hline S9 & 0.0388 & 0.0388 & 0.0523 & 0.0570 & 0.0607 & 0.0556 & 0.0468 & 0.0667 & 0.0556 & 0.0683 & 0.0596 & 0.4000 \\
\hline $\mathrm{S} 10$ & 0.0355 & 0.0356 & 0.0479 & 0.0523 & 0.0556 & 0.0510 & 0.0429 & 0.0611 & 0.0509 & 0.0626 & 0.0546 & 0.4500 \\
\hline S11 & 0.0323 & 0.0324 & 0.0436 & 0.0475 & 0.0506 & 0.0463 & 0.0390 & 0.0556 & 0.0463 & 0.0569 & 0.0496 & 0.5000 \\
\hline $\mathrm{S} 12$ & 0.0291 & 0.0291 & 0.0392 & 0.0428 & 0.0455 & 0.0417 & 0.0351 & 0.0500 & 0.0417 & 0.0512 & 0.0447 & 0.5500 \\
\hline $\mathrm{S} 13$ & 0.0258 & 0.0259 & 0.0349 & 0.0380 & 0.0404 & 0.0371 & 0.0312 & 0.0444 & 0.0370 & 0.0455 & 0.0397 & 0.6000 \\
\hline S14 & 0.0226 & 0.0227 & 0.0305 & 0.0333 & 0.0354 & 0.0324 & 0.0273 & 0.0389 & 0.0324 & 0.0398 & 0.0347 & 0.6500 \\
\hline S15 & 0.0194 & 0.0194 & 0.0261 & 0.0285 & 0.0303 & 0.0278 & 0.0234 & 0.0333 & 0.0278 & 0.0341 & 0.0298 & 0.7000 \\
\hline S16 & 0.0162 & 0.0162 & 0.0218 & 0.0238 & 0.0253 & 0.0232 & 0.0195 & 0.0278 & 0.0232 & 0.0284 & 0.0248 & 0.7500 \\
\hline S17 & 0.0129 & 0.0129 & 0.0174 & 0.0190 & 0.0202 & 0.0185 & 0.0156 & 0.0222 & 0.0185 & 0.0228 & 0.0199 & 0.8000 \\
\hline $\mathrm{S} 18$ & 0.0097 & 0.0097 & 0.0131 & 0.0143 & 0.0152 & 0.0139 & 0.0117 & 0.0167 & 0.0139 & 0.0171 & 0.0149 & 0.8500 \\
\hline S19 & 0.0065 & 0.0065 & 0.0087 & 0.0095 & 0.0101 & 0.0093 & 0.0078 & 0.0111 & 0.0093 & 0.0114 & 0.0099 & 0.9000 \\
\hline S20 & 0.0032 & 0.0032 & 0.0044 & 0.0048 & 0.0051 & 0.0046 & 0.0039 & 0.0056 & 0.0046 & 0.0057 & 0.0050 & 0.9500 \\
\hline
\end{tabular}

The influences of the new values of the weight coefficients (Table 8) on the ranking of the alternatives are presented in Figure 3.

Figure 3. Sensitivity analysis of the ranking of alternatives in 21 scenarios

The results (Figure 3) demonstrate that assigning weights to criteria in various scenarios leads to changes in the ranks of individual alternatives; hence, the model is sensitive to changes in the weight coefficients. By comparing the first three alternatives by rank (A8, A7 and A5) in the scenarios, we conclude that alternative A8 maintained the first rank in 15 scenarios, while it was ranked second in six scenarios. Alternative A7 was ranked second in three scenarios, and in one scenario it took the fourth ranking, while in 17 scenarios it was ranked third. Alternative A5 was ranked first in six scenarios and ranked third in three scenarios, while in twelve scenarios it was 
ranked second. In response to the changes in the weights of the criteria in the scenarios, the ranks and the remaining alternatives changed minimally.

From the results, we conclude that the rank of alternative A8 is credible, while there are very small differences between the second-ranked (A7) and the third-ranked (A5) alternatives. Consequently, we conclude that alternatives A7 and A5 have approximately the same significance, namely, we cannot favour either of them with certainty $(A 7 \approx A 5)$. These results are supported by the correlation of the ranks among the scenarios (Figure 4).

Figure 4. Correlation of ranks among the 21 scenarios

The correlation of the ranks was determined using the Spearman correlation coefficient (SCC). Spearman's ranking correlation coefficient is a useful tool for determining the relationship between results that are obtained via different approaches ${ }^{63}$. In this paper, Spearman's coefficient was used to determine the statistical significance of the difference between the ranges that were obtained in the scenarios. According to our analysis of the obtained correlation values (Figure 4), there is a large correlation of ranks since in 19 of the 21 scenarios, SCC values exceed 0.830 . In the remaining two scenarios, the SCC values are 0.690 and 0.738 . The mean value of the SCC over all scenarios is 0.842 , which corresponds to a large correlation of the ranks, namely, it supports the results that are presented in Table 6.

\subsection{Influence of dynamic matrices on the ranges of the alternatives}

When solving the problem, researchers encounter internal and / or external factors that, by their actions, can change the conditions or limitations of the problem. Internal changes in the decision matrix, such as the introduction of a new alternative or the elimination of an existing alternative from the set of considered alternatives, can lead to a change in the final preferences. Accordingly, in this paper, the performance analysis of the proposed model was studied under the conditions of a dynamic initial decision matrix. Six scenarios have been defined. For each scenario, the number of alternatives was changed and the obtained ranks were analysed. The scenarios are defined by removing one inferior (worst) alternative in each scenario from subsequent consideration. At the same time, within the scenario, the remaining alternatives are ranked according to the newly matched initial decision matrix.

The initial solution was generated using the TrFNN PW-MABAC model as A8 $>$ A7 $>$ A5 $>$ A2 $>$ A1 $>$ A3 $>$ A6 $>$ A4. Alternative A4 is the worst option; hence, in the first scenario, alternative A4 was eliminated from the set, and a new decision-making matrix was obtained with seven alternatives. The new decision matrix was solved again using the TrFNN PW-MABAC model, and new rankings of the alternatives $\mathrm{A} 8>\mathrm{A} 7>\mathrm{A} 5>\mathrm{A} 2>\mathrm{A} 1>\mathrm{A} 3>\mathrm{A} 6$ were obtained. In the ranking in the first scenario, A8 remains the best alternative, and A6 is the worst alternative. Repeated implementation of the described procedure resulted in the following ranks of alternatives in the remaining scenarios: $\mathrm{S} 2: \mathrm{A} 8>\mathrm{A} 7>\mathrm{A} 5>\mathrm{A} 2>\mathrm{A} 1>\mathrm{A} 3$; $\mathrm{S} 3: \mathrm{A} 8>\mathrm{A} 5>\mathrm{A} 7>\mathrm{A} 2>\mathrm{A} 1 ; \mathrm{S} 4: \mathrm{A} 8>$ A7 $>$ A5 $>$ A2; S5: A8> A7> A5 and S6: A8> A7.

Based on the obtained results, when the worst alternative is eliminated, there is no change in the best-ranked alternative in the reorganized matrix. After further modifications of the initial matrix, which were conducted via the elimination of the worst-case option, the TrFNN PW-MABAC model does not lead to changes in ranking (rank reversal) among the alternatives. Alternative A8 remained the best-ranked across all scenarios, which demonstrates the robustness and accuracy of the ranking of alternatives in a dynamic environment. 


\subsection{Comparison of the TrFNN PW-MABAC model ranks with those of other models}

In this section, we compare the results of the TrFNN PW-MABAC model with those of the TrFNN TOPSIS model, the TrFNNOWAA model and the TrFNNHWAA model. The ranges according to various VKO techniques are compared in Figure 5.

\section{Figure 5. Ranges of the alternatives}

According to the rankings of the alternatives that are obtained via the methods that are presented above, alternative A8 is ranked first by all models, except the TrFNNOWAA model, by which it is ranked second. The result is similar for alternative A7 (second-ranked). Alternative A7 is ranked second by all models except the TrFNNOWAA model, according to which it is a dominant alternative. The worst alternative is A4 for all models, while the ranks of the remaining alternatives are similar, with fewer differences. To determine the statistical significances of the differences among the ranges of the models, Spearman's correlation coefficient (SCC) was used. The results of the ranking comparison using the Spearman coefficient are presented in Table 11.

Table 11. Correlations of the ranks of the tested models

\begin{tabular}{llll}
\hline MCDM technique & TrFNN TOPSIS & TrFNNOWAA & TrFNNHWAA \\
\hline SCC & 0.988 & 0.857 & 0.857 \\
\hline MCDM technique & Fuzzy TOPSIS & Fuzzy MABAC & Rough MABAC \\
\hline SCC & 0.988 & 1.000 & 1.000 \\
\hline
\end{tabular}

The results suggest that there is a large correlation among the ranks since all SCC values that exceed 0.956 show a strong correlation ${ }^{32}$. Since in this study all SCC values exceed 0.85 , we conclude that there is a strong correlation among the proposed approach and the other tested MCDM models.

\subsection{Influence of parameter $\rho$ on the ranking results}

In the above steps, the value of parameter $\rho$ was initially assumed to be 1 ; however, the effects of changing the value of $\rho$ on the proposed TrFNNDWAA and TrFNNDWGA operators are easily observed. First, we will examine the influence of the value of parameter $\rho$ on the criterion weights. For the calculation of the criterion weights in the TrFNN PW model, we have used the TrFNNDWAA operator. The analysis demonstrates the influence of the parameter $\rho$ on the criterion weights. According to Figure 6, regardless of the value of parameter $\rho$, the criterion weights remain the same; hence, the value of parameter $\rho$ has no influence on the criterion weights.

Figure 6. Influence of parameter $\rho$ on the criterion weights

When we change the value of parameter $\rho$, the integration results typically change; hence, the ranking order may change accordingly. To examine the influence of this parameter on the results of the model, various values of $\rho$ are selected from 1 to 100. The corresponding ranking orders that are obtained for various combinations $\rho$ values are presented in Figure 7. 
Figure 7. Ranking orders for varying values of parameter $\rho$

The larger the value of parameter $\rho$, the more complex the calculation becomes, and the more the interrelations between the attributes are emphasized. DMs typically select the value of the parameter $\rho$ according to their preferences ${ }^{57}$. In decision-making, we typically recommend that the parameter value be 1 from a practical perspective, which not only is intuitionistic and simple but also can consider the internal connections between attributes. According to Figure 7, as the value of the parameter $\rho$ changes, the ranking orders of the considered alternatives remain almost the same. There is only a minor impact on the ranks of alternatives A4 and A6, but this has no influence on the final preferences in this model.

\section{Conclusions}

To avoid the risk and disruption, a safe and secure supply chain is necessary. The concept of a resilient supply chain was developed to enable managers to rethink and reconfigure their risk reduction practices. The current study proposed a decision-making structure that deploys an integrated analytical model for comparing the effective performances of suppliers. The model benefits from a multi-attribute evaluation system with respect to fuzzy neutrosophic values. We estimated the weights of supplier criteria via a new pairwise comparison approach with neutrosophic linguistic variables. Moreover, our model facilitates the responsibility of experts and supplier evaluators to release their qualitative opinions regarding the performances of suppliers. In this study, we utilize pairwise comparison of neutrosophic values. In contrast to previous studies in fuzzy supplier selection, we have applied the original Dombi aggregation operators to fuzzy neutrosophic values. In the decision process, this enables us to increase the flexibility of the information aggregation process by adjusting a parameter. The suppliers are evaluated using a fuzzy neutrosophic MABAC tool according to several resilience criteria, such as management support, supplier experience and reputation, economic stability, environment conservation, vulnerability to risk, collaboration in risk reduction, and supplier sustainability and training. Figure 2 illustrates the comprehensive procedure for resilient supplier selection under uncertainty that was utilized in our study. Experts at the DOVHER company collaborated effectively in this project, and the results were analysed and validated via several comparisons and sensitivity analysis tests. A supplier priority list is reported, and the weaknesses and capabilities of the suppliers are elaborated. We intended to resolve a problem of supplier selection under complex conditions and a lack of information. Therefore, fuzzy approach conveniently facilitated the resolution of a complex and multi-dimensional supplier selection problem. 
In the future, the proposed model can be implemented in other SC application areas, such as logistic and facility location, and technology selection with the required adoption and configuration. In addition, the model could be improved using a rough set approach or other fuzzy tools in future research works.

\section{Acknowledgments}

The authors are thankful to the experts and participants from the DOVHER company for their kind encouragement and contributions.

\section{Conflict of Interests}

The authors declare that there are no conflict of interests.

\section{References}

1. K. T. Atanassov. Intuitionistic fuzzy sets. Fuzzy Sets Syst. 1986; 20(1):87-96.

2. K. T. Atanassov, G. Gargov, Interval valued intuitionistic fuzzy sets. Fuzzy Sets Syst. 1989; 31(3):343-349.

3. W. L. Bean, J. W. Joubert, M. K. Luhandjula. Inventory management under uncertainty: A military application. Comput. Ind. Eng. 2016; 96:96-107.

4. P. Biswas, S. Pramanik, B.C. Giri. Cosine similarity measure based multi-attribute decisionmaking with trapezoidal fuzzy neutrosophic numbers. Neutrosophic Sets and Systems. 2014; 8: 46-56.

5. D. Bozanic, D. Tešić, J. Kočić. Multi-criteria FUCOM - Fuzzy MABAC model for the selection of location for construction of single-span bailey bridge. Decision Making: Applications in Management and Engineering. 2019; 2(1):132-146.

6. J.Q. Chen, Ye, J. Some single-valued neutrosophic Dombi weighted aggregation operators for multiple attribute decision-making. Symmetry. 2017; 9(6): 1-11.

7. X. Deng, Y. Hu, Y., Deng, S. Mahadevan. Supplier selection using AHP methodology extended by D numbers. Expert Syst. Appl. 2014; 41(1): 156-167.

8. J. Dombi. The Generalized Dombi operator family and the multiplicative utility function. 2009 In Soft Computing Based Modeling in Intelligent Systems (pp. 115-131). Springer, Berlin, Heidelberg.

9. J. A. Dombi. general class of fuzzy operators, the demorgan class of fuzzy operators and fuzziness measures induced by fuzzy operators. Fuzzy Sets Syst. 1982; 8(2):149-163.

10. M., Dursun, E. E. Karsak. A QFD-based fuzzy MCDM approach for supplier selection. Appl. Math. Modell.2013; 37(8):5864-5875.

11. H. Ebrahimi, M. Tadic. Optimization of dangerous goods transport in urban zone. Decision Making: Applications in Management and Engineering. 2018; 1(2):131-152.

12. H. Fazlollahtabar. An integration between fuzzy PROMETHEE and fuzzy linear program for supplier selection problem: Case study. Journal of Applied Mathematical Modelling and Computing. 2016 1(1):1-8

13. N. Foroozesh, R. Tavakkoli-Moghaddam, SM. Mousavi. Resilient supplier selection in a supply chain by a new interval-valued fuzzy group decision model based on possibilistic statistical concepts. Journal of Industrial and Systems Engineering. 2017; 10(2):113-133. 
14. K. Govindan, M. Fattahi, E. Keyvanshokooh. Supply chain network design under uncertainty: A comprehensive review and future research directions. Eur. J. Oper. Res. 2017; 263(1): 108-141.

15. A. Haldar, A. Ray, D. Banerjee, S. Ghosh. Resilient supplier selection under a fuzzy environment. International Journal of Management Science and Engineering Management. 2014; $9(2): 147-156$.

16. X. He. Typhoon disaster assessment based on Dombi hesitant fuzzy information aggregation operators. Nat. Hazards. 2018; 90(3): 1153-1175.

17. I. Igoulalene, L. Benyoucef, M. K. Tiwari. Novel fuzzy hybrid multi-criteria group decision making approaches for the strategic supplier selection problem. Expert Syst. Appl. 2015; 42(7):3342-3356.

18. V. Jain, A. K. Sangaiah, S. Sakhuja, N. Thoduka, R. Aggarwal. Supplier selection using fuzzy AHP and TOPSIS: A case study in the Indian automotive industry. Neural Computing and Applications, 2018; 29(7): 555-564.

19. C. Jana, G. Muhiuddin, M. Pal. Some Dombi aggregation of Q-rung orthopair fuzzy numbers in multiple-attribute decision making. Int. J. Intell. Syst. 2019a; 34(12): 3220-3240.

20. C. Jana, T. Senapati, M. Pal. (2019). Pythagorean fuzzy Dombi aggregation operators and its applications in multiple attribute decision-making. Int. J. Intell. Syst. 2019b; 34(9), 20192038.

21. C. Jana, T. Senapati, M. Pal, R. R. Yager. Picture fuzzy Dombi aggregation operators: Application to MADM process. Appl. Soft Comput. 2019c; 74, 99-109.

22. P. Ji, H. Y. Zhang, J. Q. Wang. A projection-based TODIM method under multi-valued neutrosophic environments and its application in personnel selection. Neural Computing and Applications. 2018; 29(1): 221-234.

23. F. R. L. Junior, L. Osiro, L. C. R. Carpinetti. A comparison between Fuzzy AHP and Fuzzy TOPSIS methods to supplier selection. Appl. Soft Comput. 2014; 21:194-209.

24. Y.R. Kahraman. Robust sensitivity analysis for multi-attribute deterministic hierarchical value models, Storming Media, Ohio. 2002.

25. K. E. Zavadskas, R. Baušys, M. Lazauskas. Sustainable assessment of alternative sites for the construction of a waste incineration plant by applying WASPAS method with single-valued neutrosophic set. Sustainability. 2015; 7(12):15923-15936.

26. Q. Khan, P. Liu, T. Mahmood, F. Smarandache, K. Ullah. Some Interval Neutrosophic Dombi Power Bonferroni Mean Operators and Their Application in Multi-Attribute Decision-Making. Symmetry 2018, 10, 459.

27. A. Kharal, A neutrosophic multi-criteria decision making method. New Mathematics and Natural Computation. 2014; 10(2):143-162.

28. C.W. Kirkwood. Strategic decision making: multi-objective decision analysis with Spreadsheets, Duxbury Press, Belmont. 1997.

29. GD. Li, D. Yamaguchi, M. Nagai. A grey-based rough decision-making approach to supplier selection. Int J Adv Manuf Technol. 2008; 36: 1032

30. P.D. Liu, J.L. Liu, S.M. Chen. Some intuitionistic fuzzy Dombi Bonferroni mean operators and their application to multi-attribute group decision making. J. Oper. Res. Soc. 2017; 69:124.

31. M. S. Memon, Y. H. Lee, S. I. Mari. Group multi-criteria supplier selection using combined grey systems theory and uncertainty theory. Expert Syst. Appl. 2015; 42(21): 7951-7959. 
32. M. Noureddine, M. Ristic. Route planning for hazardous materials transportation: Multicriteria decision making approach. Decision Making: Applications in Management and Engineering. 2019; 2(1):66-85.

33. Z. Nunic. Evaluation and selection of the PVC carpentry Manufacturer using the FUCOMMABAC model, Operational Research in Engineering Sciences: Theory and Applications, 2018; $1(1)$ : 13-28.

34. D. Pamucar, D. Bozanic. Selection of a location for the development of multimodal logistics center: Application of single-valued neutrosophic MABAC model. Operational Research in Engineering Sciences: Theory and Applications. 2019; 2(2):55-71.

35. D. Pamučar, G. Ćirović. The selection of transport and handling resources in logistics centers using Multi-Attributive Border Approximation area Comparison (MABAC). Expert Syst. Appl. 2015; 42(6):3016-3028.

36. D. Pamucar, I. Badi, S. Korica, R. Obradović. A novel approach for the selection of power generation technology using an linguistic neutrosophic combinative distance-based assessment (CODAS) method: A case study in Libya. Energies. 2018a;11(9): 2489.

37. D. Pamucar, M. Deveci, F. Canitezd, D. Bozanic. A Fuzzy Full Consistency Method-DombiBonferroni Model for Priorititizing Transportation Demand Management Measures. Appl. Soft Comput. 2020; 87, 105952.

38. D., Pamucar, I. Petrović, G. Ćirović. Modification of the Best-Worst and MABAC methods: A novel approach based on interval-valued fuzzy-rough numbers. Expert Syst. Appl. 2018c; 91:89-106.

39. D., Pamucar, Ž., Stević, E.K. Zavadskas. Integration of interval rough AHP and interval rough MABAC methods for evaluating university web pages. Appl. Soft Comput 2018b; 67:141-163.

40. J. J. Peng, J. Q. Wang, H. Y. Zhang, X. H. Chen. An outranking approach for multi-criteria decision-making problems with simplified neutrosophic sets. Appl. Soft Comput. 2014; 25: 336-346.

41. G. Petrovic, J. Mihajlovic, Z. Cojbasic, M. Madic, D. Marinkovic. Comparison of three fuzzy MCDM methods for solving the supplier selection problem. Facta Universitatis, Series: Mechanical Engineering. 2019; 17(3): 455-469.

42. S. Y. Ponomarov, M. C. Holcomb. Understanding the concept of supply chain resilience. The international journal of logistics management. 2009; 20(1):124-143.

43. D. Pramanik, A. Haldar, S. C. Mondal, S. K. Naskar, A. Ray. Resilient supplier selection using AHP-TOPSIS-QFD under a fuzzy environment. International Journal of Management Science and Engineering Management, 2017; 12(1): 45-54.

44. J. Qin, X. Liu, W. Pedrycz. An extended TODIM multi-criteria group decision making method for green supplier selection in interval type-2 fuzzy environment. Eur. J. Oper. Res. 2017; 258(2): 626-638.

45. R. Rajesh, V. Ravi. Supplier selection in resilient supply chains: a grey relational analysis approach. J. Cleaner Prod. 2015; 86, 343-359.

46. A. Rezaee, F. Dehghanian, B. Fahimnia, B. Beamon. Green supply chain network design with stochastic demand and carbon price. Ann. Oper. Res. 2017; 250(2), 463-485.

47. J. P. Ribeiro, A. Barbosa-Povoa. Supply Chain Resilience: Definitions and quantitative modelling approaches-A literature review. Comput. Ind. Eng. 2018; 115, 109-122.

48. U. Rivieccio. Neutrosophic logics: Prospects and problems. Expert Syst. Appl. 2008; 159(14): 1860-1868. 
49. J. Roy, K. Chatterjee, A. Bandyopadhyay, S. Kar. Evaluation and selection of medical tourism sites: A rough analytic hierarchy process based multi-attributive border approximation area comparison approach. Expert Systems, 2018; 35(1):e12232.

50. R. Şahin, M. A Multi-criteria neutrosophic group decision making metod based TOPSIS for supplier selection. Eprint arXiv. 2014; 1412.5077.

51. A. K. Sahu, S. Datta, S. S. Mahapatra. Evaluation and selection of resilient suppliers in fuzzy environment: Exploration of fuzzy-VIKOR. Benchmarking: An International Journal. 2016; 23(3): 651-673.

52. Y. Sheffi. Building a resilient supply chain. Harvard Business Review. 2005; 1(8):1-4.

53. L. Shi, J. Ye. Dombi Aggregation Operators of Neutrosophic Cubic Sets for Multiple Attribute Decision-Making. Algorithms 2018, 11, 29.

54. A. Shishodia, P. Verma, V. Dixit. Supplier evaluation for resilient project driven supply chain. Comput. Ind. Eng. 2019; 129: 465-478.

55. F. Smarandache. Neutrosophy: neutrosophic probability, set, and logic: analytic synthesis \& synthetic analysis. 1998.

56. F. Smarandache. Neutrosophic set-a generalization of the intuitionistic fuzzy set. International journal of pure and applied mathematics. 2005; 24(3), 287.

57. S. Sremac, Ž. Stević, D. Pamučar, M. Arsić, B. Matić. Evaluation of a Third-Party Logistics (3PL) Provider Using a Rough SWARA-WASPAS Model Based on a New Rough Dombi Agregator. Symmetry. 2018; 10(8):1-25.

58. S. Diyaley, S. Chakraborty. Optimization of multi-pass face milling parameters using metaheuristic algorithms, Facta universitatis series: Mechanical Engineering. 2019; 17(3): $365-383$

59. R. Tan, W. Zhang. Multiple attribute group decision making methods based on trapezoidal fuzzy neutrosophic numbers. J. Intell. Fuzzy Syst. 2017; 33: 2547-2564.

60. Z. P. Tian, J. Wang, J. Q. Wang, H. Y. Zhang. Simplified neutrosophic linguistic multicriteria group decision-making approach to green product development. Group Decision and Negotiation, 2017; 26(3): 597-627.

61. H. S. Tooranloo, A. Iranpour. Supplier selection and evaluation using interval-valued intuitionistic fuzzy AHP method. International Journal of Procurement Management. 2017; 10(5): 539-554.

62. S. A. Torabi, M. Baghersad, S. A. Mansouri. Resilient supplier selection and order allocation under operational and disruption risks. TRANSPORT RES E-LOG, 2015; 79, 22-48.

63. S. Veskovic, Z. Stevic, G. Stojic, M. Vasiljevic, S. Milinkovic. Evaluation of the railway management model by using a new integrated model DELPHI-SWARA-MABAC. Decision Making: Applications in Management and Engineering, 2018; 1(2): 34-50.

64. M. Wang, F. Jie, A. Abareshi. Evaluating logistics capability for mitigation of supply chain uncertainty and risk in the Australian courier firms. Asia Pacific J. Mark. Logist. 2015; 27(3): 486-498.

65. G. Wei, Y. Wei. Some single-valued neutrosophic dombi prioritized weighted aggregation operators in multiple attribute decision making. J. Intell. Fuzzy Syst. 2018; 35(2), 2001-2013.

66. J. Ye. A multicriteria decision-making method using aggregation operators for simplified neutrosophic sets. J. Intell. Fuzzy Syst. 2014; 26(5): 2459-2466.

67. L. A. Zadeh. Fuzzy sets, Information and Control, 1965; 8(3):338-353. 
68. J. Zhao, X.Y. You, H.C, Liu, S.M. Wu. An Extended VIKOR Method Using Intuitionistic Fuzzy Sets and Combination Weights for Supplier Selection. Symmetry, 2017; 9: 169.

69. U. Jüttner, S. Maklan, Supply chain resilience in the global financial crisis: an empirical study. Supply Chain Management: An International Journal. 2011; 16(4): 246-259

70. J. Ye. Trapezoidal neutrosophic set and its application to multiple attribute decision-making. Neural Computing and Applications. 2015; 26(5), 1157-1166. 
Appendix

Table A1. Aggregated matrix

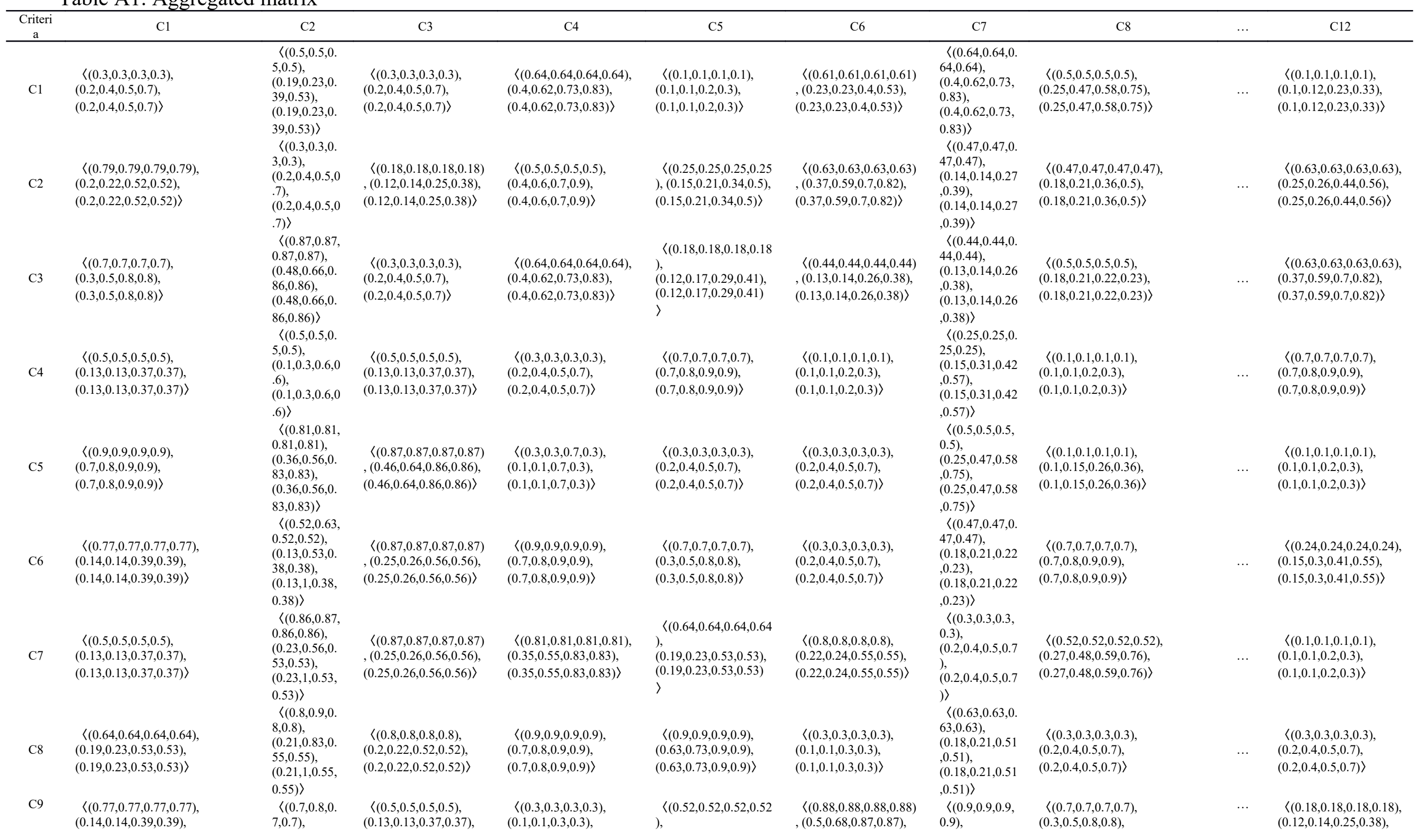


$(0.14,0.14,0.39,0.39)\rangle$

$\langle(0.88,0.88,0.88,0.88)$

$(0.56,0.73,0.87,0.87)$,

$(0.56,0.73,0.87,0.87)\rangle$

$\langle(0.82,0.82,0.82,0.82)$

$(0.36,0.56,0.83,0.83)$,

$(0.36,0.56,0.83,0.83)\rangle$

$\langle(0.9,0.9,0.9,0.9)$,

$(0.66,0.76,0.9,0.9)$,

$(0.66,0.76,0.9,0.9)\rangle$
$(0.3,0.53,0.8$

$\langle(0.87,0.8,0$ $.87,0.87)$,

$(0.48,0.55,0$

$86,0.86)$,

$(0.48,1,0.8$

$0.86)\rangle$

$\langle(0.79,0.78$,

$0.79,0.79)$,

$(0.19,0.8,0.5$

$2,0.52)$,

$(0.52)\rangle$

$0.52)\rangle$

$\langle(0.75,0.9,0$

$.75,0.75)$,
$(0.13,0.76,0$

$(0.13,0.76$,

$38,0.38)$,

0.38)> $(0.13,0.13,0.37,0.37)\rangle \quad(0.1,0.1,0.3,0.3)\rangle \quad(0.13,0.14,0.38,0.38)$

$(0.9,0.9,0.9,0.9)$,

$(0.63,0.73,0.9,0.9)$

$(0.63,0.73,0.9,0.9)\rangle$

$\langle(0.64,0.64,0.64,0.64)$ $(0.19,0.23,0.53,0.53)$

$(0.52,0.52,0.52,0.52)$ $(0.13,0.14,0.38,0.38)$ $(0.13,0.14,0.38,0.38)\rangle$
$(0.7,0,7,0.7,0.7)$

$(0.3,0.5,0.8,0.8)$,

$(0.3,0.5,0.8,0.8)\rangle$

$\langle(0.3,0.3,0.3,0.3)$, $(0.1,0.1,0.3,0.3)$ $(0.1,0.1,0.3,0.3)\rangle$

$\langle(0.64,0.64,0.64,0.64$

$(0.19,0.23,0.53,0.53)$ $(0.19,0.23,0.53,0.53)$

$\langle(0.63,0.63,0.63,0.63$

$(0.18,0.21,0.51,0.51)$ $(0.18,0.21,0.51,0.51)$ $(0.1,0.1,0.3,0.3)$ $\langle(0.9,0.9,0.9,0.9)$ $(0.7,0.8,0.9,0.9)$,

$(0.7,0.80 .9,0.9)\rangle$ $(0.5,0.68,0.87,0.87)\rangle$

$(0.79,0.79,0.79,0.79)$ $(0.2,0.22,0.52,0.52)$ $(0.2,0.22,0.52,0.52)\rangle$

$\langle(0.79,0.79,0.79,0.79)$ $(0.19,0.22,0.52,0.52)$, $(0.19,0.22,0.52,0.52)\rangle$

$\langle(0.82,0.82,0.82,0.82)$ $(0.36,0.56,0.83,0.83)$, $(0.36,0.56,0.83,0.83)\rangle$
$(0.7,0.8,0.9,0.9$

$\begin{array}{ll}(0.7,0.8,0.9,0.9 & (0.3,0.5,0.8,0.8)\rangle\end{array}$ $\langle(0.64,0.64,0$

$64,0.64)$

$(0.1,0.1,0.3,0.3)$

$(0.1,0.1,0.3,0.3)\rangle$

(0.1,0.1,0.1,0.1)

$(0.1,0.1,0.2,0.3)$

$(0.1,0.1,0.2,0.3)\rangle$

$, 0.53\rangle$

$\langle(0.87,0.87,0$

$87,0.87)$

$<(0.77,0.77,0.77,0.77)$

$(0.14,0.14,0.39,0.39)$,

$(0.14,0.14,0.39,0.39)\rangle$

$\langle(0.63,0.63,0.63,0.63)$

$(0.25,0.42,0.56,0.65)$

$(0.25,0.42,0.56,0.65)\rangle$

$0.86)\rangle$

$\langle(0.9,0.9,0.9$

$0.9)$,

$(0.7,0.8,0.9,0.9 \backslash\langle(0.7,0.7,0.7,0.7)$

$(0.3,0.5,0.8,0.8)$,

$(0.3,0.5,0.8,0.8)\rangle$
$(0.3,0.3,0.3,0.3)$ $(0.2,4,0.5,0.7)\rangle$

Table A2. Aggregated initial decision matrix $(N)$

\section{A2}

$\langle(0.1,0.1,0.1,0.1)$,

$(0.1,0.1,0.2,0.3)$,

$\langle(0.13,0.13,0.13,0.13)$

$(0.14,0.23,0.34,0.52)$

$(0.1,0.1,0.2,0.3)\rangle$

$(0.14,0.23,0.34,0.52)\rangle$

$\langle(0.36,0.36,0.36,0.36)$,

$(0.47,0.63,0.77,0.81)$,

$\langle(0.18,0.18,0.18,0.18)$

$(0.17,0.32,0.41,0.61)$

$(0.17,0.32,0.41,0.61)\rangle$

C3

$\langle(0.2,0.2,0.2,0.2)$

$(0.45,0.6,0.76,0.79)$

$(0.45,0.6,0.76,0.79)\rangle$

$\langle(0.13,0.13,0.13,0.13)$,

$(0.14,0.23,0.34,0.52)$,

$(0.14,0.23,0.34,0.52)\rangle$

$\langle(0.3,0.3,0.3,0.3)$,

$(0.2,0.4,0.5,0.7)\rangle$

$\langle(0.2,0.2,0.2,0.2)$,

$(0.48,0.62,0.78,0.8)$,

$(0.48,0.62,0.78,0.8)\rangle$

$\langle(0.5,0.5,0.5,0.5)$,
$(0.63,0.75,0.87,0.88)$,

$\langle 0.63,0.75,0.87,0.88)$
$(0.63,0.75,0.87,0.88)\rangle$

$\langle(0.14,0.14,0.14,0.14)$ $(0.47,0.6,0.77,0.78)$ $(0.47,0.6,0.77,0.78)\rangle$

A5

$(0.48,0.48,0.48$

$0.48,0.48,0.48$
$0.48)$,

$7)$

7),

$(0.62,0.74,0.86,0.8$

$$
\text { 7) }\rangle
$$

$\langle(0.14,0.14,0.14$,

$$
0.14) \text {, }
$$

$(0.47,0.6,0.77,0.77$

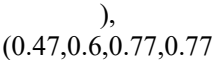

$$
)>
$$

$\langle(0.35,0.35,0.35$,

$0.35)$

$(0.28,0.49,0.59,0.8$

$$
\text { 2), }
$$

$(0.28,0.49,0.59,0.8$

$$
\text { 2)> }
$$

$\langle(0.1,0.1,0.1,0.1)$,

A6

$\langle(0.48,0.48,0.48,0.48)$,
$(0.62,0.74,0.86,0.87)$,

$(0.62,0.74,0.86,0.87)$

$(0.62,0.74,0.86,0.87)\rangle$

$\langle(0.38,0.38,0.38,0.38)$

$(0.49,0.65,0.79,0.82)$

$(0.49,0.65,0.79,0.82)\rangle$

$\langle(0.36,0.36,0.36,0.36)$,

$(0.47,0.63,0.77,0.81)$,

$(0.47,0.63,0.77,0.81)\rangle$

$(0.23,0.23,0.23,0.23)$,
$(0.61,0.73,0.86,0.86)$, $\langle(0.1,0.1,0.1,0.1)$

$(0.1,0.17,0.27,0.37)$,

$(0.1,0.17,0.27,0.37)\rangle$

$\langle(0.7,0.7,0.7,0.7)$

$(0.7,0.8,0.9,0.9)$

$(0.7,0.8,0.9,0.9)\rangle$

$\langle(0.38,0.38,0.38,0.38)$, $(0.49,0.65,0.79,0.82)$, $(0.49,0.65,0.79,0.82)\rangle$

$\langle(0.19,0.19,0.19,0.19)$, $(0.17,0.33,0.44,0.64)$, $\langle(0.36,0.36,0.36,0.36)$ $(0.47,0.63,0.77,0.81)$, $(0.47,0.63,0.77,0.81)\rangle$

$\langle(0.24,0.24,0.24,0.24)$, $(0.52,0.66,0.8,0.87)$, $(0.52,0.66,0.8,0.87)\rangle$ $(0.49,0.65,0.79,0.82)$, $(0.49,0.65,0.79,0.82)\rangle$

$\langle(0.13,0.13,0.13,0.13)$ $(0.14,0.23,0.34,0.52)$, $\langle(0.38,0.38,0.38,0.38)$ 
$(0.1,0.14,0.2$

$\langle(0.22,0.22,0.22,0.22)$ $(0.77,0.77,0.78,0.8)$

$(0.77,0.77,0.78,0.8)\rangle$

$\langle(0.5,0.5,0.5,0.5)$, $(0.63,0.75,0.87,0.88)$ $(0.63,0.75,0.87,0.88)\rangle$

$\langle(0.2,0.2,0.2,0.2)$, $(0.48,0.62,0.78,0.8)$, $(0.48,0.62,0.78,0.8)\rangle$ $\langle(0.14,0.14,0.14,0.14)$ $(0.47,0.6,0.77,0.77)$, $(0.47,0.6,0.77,0.77)\rangle$ $\langle(0.21,0.21,0.21,0.21)$, $(0.26,0.44,0.55,0.8)$ $(0.26,0.44,0.55,0.8)\rangle$

$\langle(0.25,0.25,0.25,0.25)$ $(0.63,0.74,0.86,0.87)$, $(0.63,0.74,0.86,0.87)\rangle$ $(0.62,0.74,0.86,0.87)$,

$(0.62,0.74,0.86,0.87)\rangle$

$\langle(0.1,0.1,0.1,0.1)$,

$(0.1,0.1,0.2,0.3)$,

$(0.1,0.1,0.2,0.3)\rangle$ $\langle(0.48,0.48,0.48,0.48)$,

$\langle(0.13,0.13,0.13,0.13)$ ,$(0.44,0.57,0.75,0.76)$ $(0.44,0.57,0.75,0.76)\rangle$ $(0.53,0.68,0.81,0.88)$ $(0.62,0.74,0.86,0.87)\rangle$

$\langle(0.3,0.3,0.3,0.3)$ $(0.2,0.4,0.5,0.7),(0.2,0.4,0.5,0.7)\rangle$

$\langle(0.23,0.23,0.23,0.23)$ $(0.61,0.73,0.86,0.86)$, $(0.61,0.73,0.86,0.86)\rangle$

$\langle(0.13,0.13,0.13,0.13)$,

$(0.14,0.23,0.32,0.5)$

$(0.14,0.23,0.32,0.5)\rangle$

$\langle(0.1,0.1,0.1,0.1)$,

$(0.1,0.1,0.2,0.3),(0.1,0.1,0.2,0.3)\rangle$

$\langle(0.38,0.38,0.38,0.38)$ $(0.49,0.65,0.79,0.82)$,

$(0.49,0.65,0.79,0.82)\rangle$

$\langle(0.5,0.5,0.5,0.5)$, $(0.63,0.75,0.87,0.88)$,

$(0.63,0.75,0.87,0.88)\rangle$

$\langle(0.5,0.5,0.5,0.5)$,

$(0.63,0.75,0.87,0.88)$

$(0.63,0.75,0.87,0.88)\rangle$ $\langle(0.2,0.2,0.2,0.2)$, $(0.45,0.6,0.76,0.79)$ $(0.45,0.6,0.76,0.79)\rangle$

$(0.2,0.2,0.2,0.2)$, $(0.45,0.6,0.76,0.79)$, $(0.45,0.6,0.76,0.79)\rangle$

$\langle(0.21,0.21,0.21,0.21)$ ,$(0.32,0.5,0.62,0.86)$, $(0.32,0.5,0.62,0.86)\rangle$

$\langle(0.5,0.5,0.5,0.5)$ $(0.63,0.75,0.87,0.88)$ $(0.63,0.75,0.87,0.88)\rangle$

$\langle(0.18,0.18,0.18,0.18)$ $(0.17,0.32,0.42,0.63)$ $(0.17,0.32,0.42,0.63)\rangle$

$\langle(0.13,0.13,0.13,0.13)$ $(0.13,0.22,0.32,0.5)$ $(0.13,0.22,0.32,0.5)\rangle$ $(0.49,0.65,0.79,0.82)\rangle$

$\langle(0.48,0.48,0.48,0.48)$ $(0.62,0.74,0.86,0.87)$ $(0.62,0.74,0.86,0.87)\rangle$ $(0.49,0.65,0.79,0.82)$ $(0.49,0.65,0.79,0.82)\rangle$ $\langle(0.38,0.38,0.38,0.38)$ $(0.49,0.65,0.79,0.82)$

$\langle(0.2,0.2,0.2,0.2)$, $(0.48,0.63,0.78,0.8)$, $(0.48,0.63,0.78,0.8)\rangle$

$\langle(0.44,0.44,0.44,0.44)$ ,$(0.51,0.66,0.79,0.87)$ $(0.51,0.66,0.79,0.87)\rangle$

$\langle(0.13,0.13,0.13,0.13)$ $(0.44,0.56,0.74,0.75)$, $(0.44,0.56,0.74,0.75)\rangle$

$\langle(0.2,0.2,0.2,0.2)$, $(0.77,0.77,0.78,0.8)$, $(0.77,0.77,0.78,0.8)\rangle$

$\langle(0.1,0.1,0.1,0.1)$, $(0.1,0.1,0.14,0.18)$, $(0.1,0.1,0.14,0.18)\rangle$
$14,0.24$

$\langle(0.45,0.45,0.45$, $0.45)$

$(0.53,0.68,0.81,0.8$ $8)$, $(0.53,0.68,0.81,0.8$ $8)>$

$\langle(0.19,0.19,0.19$,

$$
0.19)
$$

$(0.17,0.33,0.44,0.6$

$$
\text { 4), }
$$

$(0.17,0.33,0.44,0.6$

$$
\text { 4) }>
$$

$\langle(0.3,0.3,0.3,0.3)$, $(0.2,0.4,0.5,0.7)$,

$(0.2,0.4,0.5,0.7)\rangle$

$\langle(0.5,0.5,0.5,0.5)$ $(0.4,0.6,0.7,0.9)$, $(0.4,0.6,0.7,0.9)\rangle$

$\langle(0.36,0.36,0.36$,

$$
0.36 \text { ), }
$$

$0.47,0.63,0.77,0.8$ $1)$

1), $63,0.77,0.8$

$$
\text { 1)〉 }
$$

$\langle(0.13,0.13,0.13$,

$$
0.13)
$$

$(0.14,0.23,0.34,0.5$

$(0.14,0.23,0.34,0.5$

$$
\text { 2) }>
$$

$\langle(0.3,0.3,0.3,0.3)$, $(0.2,0.4,0.5,0.7)$,

$(0.2,0.4,0.5,0.7)\rangle$

$\langle(0.13,0.13,0.13$, $0.13)$

$(0.13,0.27,0.38,0.5$

$(0.13,0.27,0.38,0.5$

$(0.61,0.73,0.86,0.86)\rangle$

$\langle(0.5,0.5,0.5,0.5)$, $(0.78,0.81,0.86,0.87)$ $(0.78,0.81,0.86,0.87)\rangle$

$\langle(0.61,0.61,0.61,0.61)$, $(0.64,0.76,0.87,0.9)$,

$(0.64,0.76,0.87,0.9)\rangle$

$\langle(0.19,0.19,0.19,0.19)$, $(0.17,0.33,0.44,0.64)$

$(0.17,0.33,0.4$

$\langle(0.3,0.3,0.3,0.3)$,

$(0.2,0.4,0.5,0.7)$

$(0.2,0.4,0.5,0.7)\rangle$

$\langle(0.48,0.48,0.48,0.48)$, $(0.62,0.74,0.86,0.87)$,

$(0.62,0.74,0.86,0.87)\rangle$

$\langle(0.22,0.22,0.22,0.22)$, $(0.49,0.64,0.78,0.86)$

$(0.49,0.64,0.78,0.86)\rangle$

$\langle(0.23,0.23,0.23,0.23)$, $(0.61,0.73,0.86,0.86)$, $(0.61,0.73,0.86,0.86)\rangle$

$\langle(0.48,0.48,0.48,0.48)$, $(0.62,0.74,0.86,0.87)$ $(0.62,0.74,0.86,0.87)\rangle$
$(0.36,0.36,0.36,0.36)$ $(0.47,0.63,0.77,0.81)$, $(0.47,0.63,0.77,0.81)\rangle$

$\langle(0.1,0.1,0.1,0.1)$, $(0.1,0.1,0.2,0.3)$ $(0.1,0.1,0.2,0.3)\rangle$

$\langle(0.7,0.7,0.7,0.7)$, $(0.7,0.8,0.9,0.9)$, $(0.7,0.8,0.9,0.9)\rangle$

$\langle(0.19,0.19,0.19,0.19)$ $(0.26,0.45,0.56,0.8)$, $(0.26,0.45,0.56,0.8)\rangle$

$\langle(0.42,0.42,0.42,0.42)$ $(0.35,0.56,0.66,0.88)$,

$(0.35,0.56,0.66,0.88)\rangle$

$\langle(0.13,0.13,0.13,0.13)$ $(0.14,0.23,0.34,0.52)$, $(0.14,0.23,0.34,0.52)\rangle$

$\langle(0.34,0.34,0.34,0.34)$, $(0.27,0.48,0.58,0.81)$, $(0.27,0.48,0.58,0.81)\rangle$ $\langle(0.38,0.38,0.38,0.38)$ $(0.49,0.65,0.79,0.82)$, $(0.49,0.65,0.79,0.82)\rangle$ $\langle(0.13,0.13,0.13,0.13)$ $(0.13,0.22,0.32,0.5)$, $(0.13,0.22,0.32,0.5)\rangle$

$\langle(0.7,0.7,0.7,0.7)$, $(0.7,0.8,0.9,0.9)$, $(0.7,0.8,0.9,0.9)\rangle$

$\langle(0.38,0.38,0.38,0.38)$, $(0.49,0.65,0.79,0.82)$, $(0.49,0.65,0.79,0.82)\rangle$ $\langle(0.7,0.7,0.7,0.7)$ $(0.7,0.8,0.9,0.9)$, $(0.7,0.8,0.9,0.9)\rangle$

$\langle(0.7,0.7,0.7,0.7)$, $(0.7,0.8,0.9,0.9)$, $(0.7,0.8,0.9,0.9)\rangle$

$\langle(0.56,0.56,0.56,0.56)$ $(0.56,0.7,0.82,0.9)$, $(0.56,0.7,0.82,0.9)\rangle$

$\langle(0.1,0.1,0.1,0.1)$ $(0.1,0.1,0.2,0.3)$, $(0.1,0.1,0.2,0.3)\rangle$

$\langle(0.5,0.5,0.5,0.5)$ $(0.8,0.82,0.86,0.87)$ $(0.8,0.82,0.86,0.87)\rangle$ 4) $>$ 
Table A3. Weighted matrix $(D)$

\begin{tabular}{|c|c|c|c|c|c|c|c|c|}
\hline Criteria & A1 & A2 & A3 & A4 & A5 & A6 & A7 & A8 \\
\hline $\mathrm{C} 1$ & $\begin{array}{c}(0.01,0.01 \\
, 0.01,0.01), \\
(0.88,0.88,0 . \\
91,0.93), \\
(0.88,0.88,0 . \\
91,0.93)\rangle\end{array}$ & $\begin{array}{c}\langle(0.01,0.01,0.01,0.01), \\
(0.89,0.92,0.94,0.96), \\
(0.89,0.92,0.94,0.96)\rangle\end{array}$ & $\begin{array}{c}\langle(0.07,0.07,0.0 \\
7,0.07), \\
(0.98,0.99,0.99, \\
0.99), \\
(0.98,0.99,0.99, \\
0.99)\rangle\end{array}$ & $\begin{array}{l}\langle(0.04,0.04,0.04,0.04) \\
(0.97,0.98,0.99,0.99), \\
(0.97,0.98,0.99,0.99)\rangle\end{array}$ & $\begin{array}{l}\langle(0.04,0.04,0.04,0.04) \\
(0.97,0.98,0.99,0.99) \\
(0.97,0.98,0.99,0.99)\rangle\end{array}$ & $\begin{array}{c}\langle(0.04,0.04,0.04,0.0 \\
4), \\
(0.97,0.98,0.99,0.99), \\
(0.97,0.98,0.99,0.99) \\
\rangle\end{array}$ & $\begin{array}{c}\langle(0.01,0.01,0.01,0.01), \\
(0.88,0.91,0.93,0.95), \\
(0.88,0.91,0.93,0.95)\rangle\end{array}$ & $\begin{array}{c}\langle(0.03,0.03,0.03,0.03) \\
(0.96,0.98,0.99,0.99), \\
(0.96,0.98,0.99,0.99)\rangle\end{array}$ \\
\hline $\mathrm{C} 2$ & $\begin{array}{c}\langle(0.01,0.01 \\
, 0.01,0.01), \\
(0.9,0.94,0.9 \\
5,0.97), \\
(0.9,0.94,0.9 \\
5,0.97)\rangle\end{array}$ & $\begin{array}{c}\langle(0.03,0.03,0.03,0.03) \\
(0.96,0.97,0.99,0.99), \\
(0.96,0.97,0.99,0.99)\rangle\end{array}$ & $\begin{array}{c}\langle(0.03,0.03,0.0 \\
3,0.03), \\
(0.96,0.98,0.99, \\
0.99), \\
(0.96,0.98,0.99, \\
0.99)\rangle\end{array}$ & $\begin{array}{l}\langle(0.01,0.01,0.01,0.01) \\
(0.96,0.97,0.99,0.99) \\
(0.96,0.97,0.99,0.99)\rangle\end{array}$ & $\begin{array}{l}\langle(0.01,0.01,0.01,0.01) \\
(0.96,0.97,0.99,0.99) \\
(0.96,0.97,0.99,0.99)\rangle\end{array}$ & $\begin{array}{c}\langle(0.03,0.03,0.03,0.0 \\
3), \\
(0.96,0.98,0.99,0.99) \\
(0.96,0.98,0.99,0.99) \\
\rangle\end{array}$ & $\begin{array}{c}\langle(0.07,0.07,0.07,0.07), \\
(0.98,0.99,0.99,0.99), \\
(0.98,0.99,0.99,0.99)\rangle\end{array}$ & $\begin{array}{c}\langle(0.03,0.03,0.03,0.03), \\
(0.96,0.97,0.99,0.99), \\
(0.96,0.97,0.99,0.99)\rangle\end{array}$ \\
\hline C3 & $\begin{array}{c}\langle(0.02,0.02 \\
, 0.02,0.02), \\
(0.94,0.96,0 . \\
98,0.98) \\
(0.94,0.96,0 . \\
98,0.98)\rangle\end{array}$ & $\begin{array}{c}\langle(0.01,0.01,0.01,0.01) \\
(0.86,0.9,0.92,0.95) \\
(0.86,0.9,0.92,0.95)\rangle\end{array}$ & $\begin{array}{c}\langle(0.03,0.03,0.0 \\
3,0.03), \\
(0.88,0.93,0.95, \\
0.97), \\
(0.88,0.93,0.95, \\
0.97)\rangle\end{array}$ & $\begin{array}{c}\langle(0.02,0.02,0.02,0.02) \\
(0.95,0.96,0.98,0.98) \\
(0.95,0.96,0.98,0.98)\rangle\end{array}$ & $\begin{array}{c}\langle(0.03,0.03,0.03,0.03) \\
(0.91,0.95,0.96,0.99), \\
(0.91,0.95,0.96,0.99)\rangle\end{array}$ & $\begin{array}{c}\langle(0.03,0.03,0.03,0.0 \\
3), \\
(0.94,0.96,0.98,0.98) \\
(0.94,0.96,0.98,0.98) \\
\rangle\end{array}$ & $\begin{array}{c}\langle(0.04,0.04,0.04,0.04), \\
(0.95,0.97,0.98,0.99), \\
(0.95,0.97,0.98,0.99)\rangle\end{array}$ & $\begin{array}{c}\langle(0.02,0.02,0.02,0.02), \\
(0.95,0.97,0.98,0.99), \\
(0.95,0.97,0.98,0.99)\rangle\end{array}$ \\
\hline $\mathrm{C} 4$ & $\begin{array}{c}\langle(0.04,0.04 \\
, 0.04,0.04), \\
(0.94,0.96,0 . \\
98,0.98), \\
(0.94,0.96,0 . \\
98,0.98)\rangle\end{array}$ & $\begin{array}{c}\langle(0.02,0.02,0.02,0.02) \\
(0.94,0.96,0.98,0.98), \\
(0.94,0.96,0.98,0.98)\rangle\end{array}$ & $\begin{array}{c}\langle(0.01,0.01,0.0 \\
1,0.01), \\
(0.85,0.88,0.91, \\
0.94), \\
(0.85,0.88,0.91, \\
0.94)\rangle\end{array}$ & $\begin{array}{l}\langle(0.02,0.02,0.02,0.02) \\
(0.96,0.98,0.99,0.99) \\
(0.96,0.98,0.99,0.99)\rangle\end{array}$ & $\begin{array}{l}\langle(0.01,0.01,0.01,0.01) \\
(0.83,0.85,0.89,0.91) \\
(0.83,0.85,0.89,0.91)\rangle\end{array}$ & $\begin{array}{c}\langle(0.02,0.02,0.02,0.0 \\
2), \\
(0.96,0.97,0.99,0.99) \\
(0.96,0.97,0.99,0.99) \\
\rangle\end{array}$ & $\begin{array}{c}\langle(0.02,0.02,0.02,0.02), \\
(0.86,0.91,0.93,0.96), \\
(0.86,0.91,0.93,0.96)\rangle\end{array}$ & $\begin{array}{c}\langle(0.01,0.01,0.01,0.01), \\
(0.85,0.89,0.91,0.95), \\
(0.85,0.89,0.91,0.95)\rangle\end{array}$ \\
\hline C5 & $\begin{array}{c}\langle(0.02,0.02 \\
, 0.02,0.02), \\
(0.98,0.98,0 . \\
98,0.98) \\
(0.98,0.98,0 . \\
98,0.98)\rangle\end{array}$ & $\begin{array}{c}\langle(0.06,0.06,0.06,0.06) \\
(0.96,0.97,0.99,0.99), \\
(0.96,0.97,0.99,0.99)\rangle\end{array}$ & $\begin{array}{c}\langle(0.01,0.01,0.0 \\
1,0.01), \\
(0.93,0.95,0.97, \\
0.98), \\
(0.93,0.95,0.97, \\
0.98)\rangle\end{array}$ & $\begin{array}{c}\langle(0.05,0.05,0.05,0.05) \\
(0.95,0.97,0.98,0.99) \\
(0.95,0.97,0.98,0.99)\rangle\end{array}$ & $\begin{array}{c}\langle(0.05,0.05,0.05,0.05) \\
(0.95,0.97,0.98,0.99) \\
(0.95,0.97,0.98,0.99)\rangle\end{array}$ & $\begin{array}{c}\langle(0.06,0.06,0.06,0.0 \\
6), \\
(0.98,0.98,0.99,0.99) \\
(0.98,0.98,0.99,0.99) \\
\rangle\end{array}$ & $\begin{array}{c}\langle(0.04,0.04,0.04,0.04), \\
(0.94,0.96,0.98,0.98), \\
(0.94,0.96,0.98,0.98)\rangle\end{array}$ & $\begin{array}{c}\langle(0.01,0.01,0.01,0.01), \\
(0.84,0.87,0.9,0.94), \\
(0.84,0.87,0.9,0.94)\rangle\end{array}$ \\
\hline C6 & $\begin{array}{c}\langle(0.05,0.05 \\
, 0.05,0.05) \\
(0.96,0.98,0 . \\
99,0.99) \\
(0.96,0.98,0 . \\
99,0.99)\rangle\end{array}$ & $\begin{array}{c}\langle(0.03,0.03,0.03,0.03) \\
(0.88,0.93,0.95,0.97) \\
(0.88,0.93,0.95,0.97)\rangle\end{array}$ & $\begin{array}{c}\langle(0.02,0.02,0.0 \\
2,0.02), \\
(0.94,0.96,0.98, \\
0.98), \\
(0.94,0.96,0.98, \\
0.98)\rangle\end{array}$ & $\begin{array}{l}\langle(0.02,0.02,0.02,0.02) \\
(0.94,0.96,0.98,0.98) \\
(0.94,0.96,0.98,0.98)\rangle\end{array}$ & $\begin{array}{l}\langle(0.02,0.02,0.02,0.02) \\
(0.87,0.92,0.94,0.96) \\
(0.87,0.92,0.94,0.96)\rangle\end{array}$ & $\begin{array}{c}\langle(0.07,0.07,0.07,0.0 \\
7), \\
(0.96,0.98,0.99,0.99), \\
(0.96,0.98,0.99,0.99) \\
\rangle\end{array}$ & $\begin{array}{c}\langle(0.01,0.01,0.01,0.01), \\
(0.83,0.83,0.88,0.91), \\
(0.83,0.83,0.88,0.91)\rangle\end{array}$ & $\begin{array}{c}\langle(0.09,0.09,0.09,0.09), \\
(0.97,0.98,0.99,0.99), \\
(0.97,0.98,0.99,0.99)\rangle\end{array}$ \\
\hline C7 & $\begin{array}{c}\langle(0.02,0.02 \\
, 0.02,0.02) \\
(0.95,0.97,0 . \\
98,0.98) \\
(0.95,0.97,0 . \\
98,0.98)\rangle\end{array}$ & $\begin{array}{c}\langle(0.02,0.02,0.02,0.02) \\
(0.97,0.98,0.99,0.99) \\
(0.97,0.98,0.99,0.99)\rangle\end{array}$ & $\begin{array}{c}\langle(0.02,0.02,0.0 \\
2,0.02), \\
(0.93,0.95,0.97 \\
0.99), \\
(0.93,0.95,0.97 \\
0.99)\rangle\end{array}$ & $\begin{array}{l}\langle(0.02,0.02,0.02,0.02) \\
(0.95,0.97,0.98,0.99) \\
(0.95,0.97,0.98,0.99)\rangle\end{array}$ & $\begin{array}{c}\langle(0.02,0.02,0.02,0.02) \\
(0.9,0.94,0.95,0.98) \\
(0.9,0.94,0.95,0.98)\rangle\end{array}$ & $\begin{array}{c}\langle(0.01,0.01,0.01,0.0 \\
1) \\
(0.89,0.93,0.95,0.97) \\
(0.89,0.93,0.95,0.97) \\
\rangle\end{array}$ & $\begin{array}{c}\langle(0.08,0.08,0.08,0.08), \\
(0.98,0.98,0.99,0.99), \\
(0.98,0.98,0.99,0.99)\rangle\end{array}$ & $\begin{array}{c}\langle(0.03,0.03,0.03,0.03), \\
(0.95,0.97,0.98,0.99), \\
(0.95,0.97,0.98,0.99)\rangle\end{array}$ \\
\hline C8 & $\begin{array}{c}\langle(0.01,0.01 \\
, 0.01,0.01), \\
(0.93,0.95,0 . \\
97,0.97) \\
(0.93,0.95,0 . \\
97,0.97)\rangle\end{array}$ & $\begin{array}{c}\langle(0.01,0.01,0.01,0.01) \\
(0.83,0.87,0.9,0.94) \\
(0.83,0.87,0.9,0.94)\rangle\end{array}$ & $\begin{array}{c}\langle(0.06,0.06,0.0 \\
6,0.06), \\
(0.96,0.97,0.99, \\
0.99), \\
(0.96,0.97,0.99, \\
0.99)\rangle\end{array}$ & $\begin{array}{c}\langle(0.05,0.05,0.05,0.05) \\
(0.94,0.96,0.98,0.99) \\
(0.94,0.96,0.98,0.99)\rangle\end{array}$ & $\begin{array}{c}\langle(0.06,0.06,0.06,0.06) \\
(0.92,0.95,0.97,0.99) \\
(0.92,0.95,0.97,0.99)\rangle\end{array}$ & $\begin{array}{c}\langle(0.03,0.03,0.03,0.0 \\
3), \\
(0.86,0.92,0.94,0.97) \\
(0.86,0.92,0.94,0.97) \\
\rangle\end{array}$ & $\begin{array}{c}\langle(0.02,0.02,0.02,0.02), \\
(0.88,0.93,0.95,0.98), \\
(0.88,0.93,0.95,0.98)\rangle\end{array}$ & $\begin{array}{c}\langle(0.11,0.11,0.11,0.11), \\
(0.97,0.98,0.99,0.99), \\
(0.97,0.98,0.99,0.99)\rangle\end{array}$ \\
\hline C9 & $\begin{array}{c}\langle(0.02,0.02 \\
, 0.02,0.02) \\
(0.9,0.94,0.9 \\
5,0.98),\end{array}$ & $\begin{array}{l}\langle(0.01,0.01,0.01,0.01), \\
(0.83,0.83,0.88,0.91) \\
(0.83,0.83,0.88,0.91)\rangle\end{array}$ & $\begin{array}{c}\langle(0.02,0.02,0.0 \\
2,0.02), \\
(0.87,0.91,0.93, \\
0.96),\end{array}$ & $\begin{array}{c}\langle(0.01,0.01,0.01,0.01) \\
(0.94,0.95,0.98,0.98) \\
(0.94,0.95,0.98,0.98)\rangle\end{array}$ & $\begin{array}{c}\langle(0.04,0.04,0.04,0.04) \\
(0.94,0.96,0.98,0.98) \\
(0.94,0.96,0.98,0.98)\rangle\end{array}$ & $\begin{array}{c}\langle(0.05,0.05,0.05,0.0 \\
5) \\
(0.96,0.98,0.99,0.99), \\
(0.96,0.98,0.99,0.99)\end{array}$ & $\begin{array}{l}\langle(0.04,0.04,0.04,0.04), \\
(0.92,0.95,0.97,0.99), \\
(0.92,0.95,0.97,0.99)\rangle\end{array}$ & $\begin{array}{c}\langle(0.09,0.09,0.09,0.09), \\
(0.97,0.98,0.99,0.99), \\
(0.97,0.98,0.99,0.99)\rangle\end{array}$ \\
\hline
\end{tabular}


C11 $\quad(0.96,0.97$, 99,0.99), $(0.96,0.97,0$

99,0.99)〉

$\langle(0.01,0.01$

$, 0.01,0.01)$,

$\begin{array}{cc} & (0.74,0.74,0 . \\ & 81,0.86),\end{array}$ $81,0.86)$,
$(0.74,0.74,0$.

$(0.93,0.96,0.98,0.98)$

$(0.93,0.96,0$

$\langle(0.05,0.05,0.05,0.05)$,
$(0.93,0.96,0.98,0.98)$,

$(0.93,0.96,0.98,0.98)\rangle$

$(0.82,0.86,0.89$

$0.93)\rangle$

$\langle(0.05,0.05,0.0$

$5,0.05)$

$\langle(0.06,0.06,0.06,0.06)$

$(0.96,0.98,0.99,0.99)$,

$(0.96,0.98,0.99,0.99)\rangle$

$(0.96,0.97,0.99$

$0.99)$,
$0.96,0.97,0.99$,

$0.99)\rangle$

$(0.98,0.98,0.98,0.98)\rangle$

$\langle(0.09,0.09,0.09,0.09)$,

$(0.94,0.96,0.98,0.98)$

$\langle(0.06,0.06,0.0$

$6,0.06)$

$(0.91,0.95,0.97$

$0.98)$

$0.98)\rangle$ $\langle(0.02,0.02,0.02,0.02)$,
$(0.98,0.98,0.98,0.98)$,

$\langle(0.01,0.01,0.01,0.01)$,

$(0.74,0.74,0.77,0.8)$,

$(0.03,0.03,0.03,0.03)$

$\langle(0.03,0.03,0.03,0.03)$,
$(0.87,0.92,0.94,0.97)$,

$(0.87,0.92,0.94,0.97)\rangle$

$(0.74,0.74,0.77,0.8)\rangle$

$(0.77,0.85,0.88,0.92)$,
$(0.82,0.87,0.9,0.94)$ $\langle(0.01,0.01,0.01,0.01)$

$\langle(0.02,0.02,0.02,0.0$

$2)$,
$(0.93,0.96,0.98,0.98)$,

$\langle(0.01,0.01,0.01,0.01)$,
$(0.82,0.87,0.9,0.94)$,

$(0.82,0.87,0.9,0.94)\rangle$

$\langle(0.08,0.08,0.08,0.08)$,

$(0.94,0.97,0.98,0.99)$,

$$
>
$$

$\langle(0.02,0.02,0.02,0.0$

$2)$,
$(0.96,0.97,0.99,0.99)$,

$(0.89,0.94,0.95,0.98)$

$(0.89,0.94,0.95,0.98)\rangle$

$\langle(0.01,0.01,0.01,0.01)$,

$(0.82,0.82,0.87,0.9)$,

$8)$,

(0.94,0.96,0.98,0.98)

$\langle(0.06,0.06,0.06,0.06)$,

$(0.91,0.95,0.97,0.98)$,

$(0.91,0.95,0.97,0.98)\rangle$ 